\title{
Aislamiento y caracterización molecular de cepas fitoplanctónicas obtenidas en Engabao, Guayas-Ecuador.
}

Isolation and molecular characterization of phytoplankton strains obtained in Engabao, Guayas-Ecuador.

\section{Daniela Melissa Cabrera Gavilanes ${ }^{1 *}$, Efrén Santos Ordóñez ${ }^{2-3}$ \& Geovanna Parra-Ríofrío ${ }^{1-4}$}

\author{
${ }^{1}$ Facultad de Ciencias Naturales, Universidad de Guayaquil, 090601 Guayaquil, Ecuador \\ ${ }^{2}$ Facultad de Ciencias de la Vida, Campus Gustavo Galindo, ESPOL Polytechnic University, \\ Escuela Superior Politécnica del Litoral, ESPOL, Guayaquil, Ecuador. \\ ${ }^{3}$ Centro de Investigaciones Biotecnológicas del Ecuador, Campus Gustavo Galindo, ESPOL \\ Polytechnic University, Escuela Superior Politécnica del Litoral, ESPOL, Guayaquil, Ecuador \\ ${ }^{4}$ Laboratorio de Acuacultura, Facultad de Ciencias Naturales, Universidad de Guayaquil, \\ 090601 Guayaquil, Ecuador.
}

Recibido 3 agosto 2021; revisado 26 agosto 2021; aceptado 20 de diciembre 2021

Disponible en línea 30 de diciembre 2021.

\section{Resumen}

El interés industrial en microorganismos fitoplanctónicos como microalgas y cianobacterias se debe al elevado potencial biotecnológico que poseen en sintetizar compuestos bioactivos, a la facilidad de adaptarse a diferentes fuentes de nutrientes, condiciones extremas de supervivencia y a la capacidad bioabsorbente de metales pesados, principalmente en aguas residuales. El objetivo del presente estudio consistió en aislar y caracterizar fenotípica y genotípicamente microorganismos fitoplanctónicos de piscinas de estabilización de Engabao, Guayas-Ecuador, mediante el uso de diferentes medios de cultivos y de los marcadores moleculares ITS, ITS2, LSU y $16 \mathrm{~S}$ RNAr. Los resultados del cultivo celular durante siete días mostraron que la microalga Chls1 con medio BG11 pH 7.8 alcanzó $25.4 \times 10^{6}$ cel mL , la cianobacteria Syn1 fue de $340.6 \times 10^{6} \mathrm{cel} \mathrm{mL}^{-1}$, mientras que para Nod1 se empleó análisis de clorofila $a$ alcanzando al séptimo día $6.33 \mu \mathrm{g} \mathrm{mL}^{-1}$. Los estudios moleculares se realizaron empleando un protocolo modificado de extracción y purificación de ADNg obteniendo una óptima concentración y calidad del ADN para las tres cepas: Chls1 $146 \mathrm{ng} \mu \mathrm{L}^{-1}$, Syn1 $326 \mathrm{ng} \mu \mathrm{L}^{-1}$ y Nod1 $158.8 \mathrm{ng} \mu \mathrm{L}^{-1}$. El uso de análisis polifásicos en base a caracteres morfológicos y ADNg de las cepas, se amplificó por PCR y se secuenció; las cepas identificadas fenotípica y genotípicamente mediante los primers ITS2, ITS y LSU corresponde a la microalga Chlorella sorokiniana con 99,48\%, 99,07\% y 99,77\% de similitud de identidad, mientras que los aislados cianobacterianos Synechococcus sp. y Nodosilinea sp. con el análisis de la región 16S RNAr presenta porcentajes de identidad de 97,47\% y 99,83\%; a pesar de no emplear cebadores específicos para estos microorganismos, el uso de varias regiones, aumenta la confiablidad en la identificación taxonómica y filogenética; estas especies poseen alto potencial biotecnológico y de gran impacto económico.

Palabras claves: Cepas fitoplanctónicas, Chlorella sorokiniana, Synechococcus sp., Nodosilinea sp.

\section{Abstract}

The industrial interest in phytoplanktonic microorganisms such as microalgae and cyanobacteria are due to the high biotechnological potential they have in synthesizing bioactive compounds, ease of adapting to different sources of nutrients, extreme survival conditions and the bioabsorbent capacity of heavy metals mainly in wastewater. The objective of this study was to isolate and characterize phenotypically and genotypically phytoplanktonic microorganisms from stabilization pools in Engabao, Guayas-Ecuador, using different culture media and molecular markers ITS, ITS2, LSU and 16S RNAr. The results of the cell culture during seven days showed the Chls1 microalgae with BG11 pH 7.8 medium reached $25.4 \times 106$ cells $\mathrm{mL}^{-1}$, the cyanobacterium Syn1 was $340.6 \times 106$ cells $\mathrm{mL}^{-1}$, while for Nod1 chlorophyll analysis was used to reach on the seventh day $6.33 \mu \mathrm{g} \mathrm{mL} \mathrm{m}^{-1}$. Molecular studies were carried out using a modified gDNA extraction and purification protocol, obtaining optimal DNA concentration and quality for the three strains: Chls1 $146 \mathrm{ng} \mu \mathrm{L}^{-1}$, Syn1 $326 \mathrm{ng} \mu \mathrm{L}^{-1}$ and

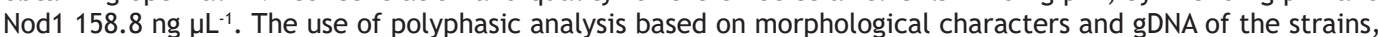
was amplified by PCR and sequenced; the strains identified phenotypically and genotypically by the primers ITS2, ITS and LSU correspond to the microalgae Chlorella sorokiniana with $99.48 \%, 99.07 \%$ and $99.77 \%$ identity similarity, while the cyanobacterial isolates Synechococcus sp. and Nodosilinea sp. with the analysis of the 16S RNAr region, it presents identity percentages of $97.47 \%$ and $99.83 \%$; despite not using specific primers for these microorganisms, the use of several regions increases the reliability of taxonomic and phylogenetic identification; these species have a high biotechnological potential and a great economic impact. Keywords: Chlorella sorokiniana, Nodosilinea sp., phytoplanktonic strains, Synechococcus sp.

* Correspondencia del autor:

E-mail: daniela.melissac@ug.edu.ec 


\section{Introducción}

El fitoplancton se caracteriza por ser un conjunto de microorganismos fotosintéticos oxigénicos, esta característica se debe a la composición bioquímica del aparato fotosintético (Ende \& Noke, 2019; Lee, 2008; Smetana et al., 2017), asimismo, se encuentran en todos las hábitats terrestres y acuáticos del mundo, siendo la base de la cadena alimenticia (Andrade et al., 2009; Barsanti \& Gualtieri, 2014; Wehr et al., 2015). Pertenecen a un diverso grupo polifilético de microorganismos procariotas y eucariotas, sistematizados en distintos grupos por sus pigmentos fotosintéticos, caracteres morfológicos y moleculares, encontrando dentro de este grupo a microalgas y cianobacterias (Begum et al., 2016; Colla \& Rouphael, 2020; Jeffrey et al., 2011).

Las microalgas y cianobacterias han sido utilizadas por los seres humanos, en nutracéutica (Nicoletti, 2016; Vieira et al., 2020), cosmecéutica (Pangestuti et al., 2020; Vieira et al., 2020), biocombustibles (Brennan \& Owende, 2010; Chaïb et al., 2021) industria agrícola y alimentación (Dufossé et al., 2005; Gantar \& Svirčev, 2008). En años recientes, la investigación se ha enfocado en las moléculas que sintetizan estos organismos y que tienen un alto valor bioactivo (Demay et al., 2019; Gouveia et al., 2010; Skulberg, 2000; Vijayakumar \& Menakha, 2015).

La plasticidad fisiológica de las microalgas y cianobacterias permite determinar la variabilidad para estudios de biodiversidad y biotecnología a través de recursos genéticos (Darienko et al., 2015; Solovchenko et al., 2015; Üveges et al., 2012). Los estudios de bioprospección, relacionados con el aislamiento, cultivo e identificación son de importancia biológica. Las taxa de los grupos mencionados han sido caracterizadas taxonómicamente dependiendo de la morfología, sin embargo, una minoría han sido caracterizadas molecularmente (Berrendero et al., 2008; Conklin et al., 2020; Molins et al., 2018; Neofotis et al., 2016).

El uso de herramientas moleculares permite obtener mayor precisión en la identificación taxonómica y filogenética, además, interviene en áreas como: biomedicina, control de plagas, detección de especies invasoras, estudios relacionados sobre la conservación de la biodiversidad $\mathrm{y}$, sobre todo, determinar su potencial biológico (Darienko et al., 2015; Falciatore et al., 2020; Padisák et al., 2015).

Una cepa de Chlamydomonas se identificó mediante la región ITS, posteriormente, se modificó genéticamente con el fin de aumentar la producción y las aplicaciones biotecnológicas, fue la primera especie de microrganismos fitoplanctónicos identificada molecularmente (Brodie \& Lewis, 2007; Fernández et al., 1989). Se empleó la técnica de PCR con el primer LSU con el fin de determinar la heterogeneidad microalgal de muestras de aguas continentales de acceso público de Singapur, identificando 17 géneros de microalgas de 94 aislados, predominando Scenedesmus spp., Chlorella spp., Micractinium spp. y Chlamydomonas spp., además, 16 de los aislados fueron registrados por primera vez en la región, los datos obtenidos tienen gran importancia ecológica y biotecnológica (Lloyd et al., 2021)

El uso de la región $16 \mathrm{~S}$ ARNr se emplea ampliamente en la identificación de cianobacterias, Osorio et al. (2014) emplea el gen 16S ARNr para la identificación taxonómica de siete nuevas especies crípticas del orden Pseudanabaenales. Sin embargo, el uso de cebadores universales como $16 \mathrm{~S}$ ARNr y primers de cianotoxinas permite obtener mayor robustez en la identificación taxonómica (Valenzuela-González et al., 2015).

La comuna Engabao posee varias piscinas o lagunas de oxidación, que son tratamientos de aguas residuales de desechos biológicos creados por los mismos comuneros, debido a que, no poseen un sistema de agua potable y tratamiento de aguas servidas. Por lo que, es de vital importancia determinar taxonómicamente mediante herramientas moleculares que microorganismos se desarrollan en ese lugar, cuáles serían sus posibles usos en base a la problemática establecida y cómo emplear dichas especies para el tratamiento de las piscinas de oxidación, brindándoles soluciones para mejorar la calidad de vida y la economía de los pobladores.

Considerando todos estos antecedentes, el objetivo del estudio es aislar y caracterizar molecularmente cepas fitoplanctónicas obtenidas en Engabao, provincia del Guayas, costa de Ecuador.

\section{Materiales y métodos}

\section{Fase de Campo}

\section{Colección y transporte de las muestras}

Las muestras de agua fueron colectadas durante el mes de noviembre de 2020 en las piscinas de oxidación de la Comuna Engabao, -2.6102778, -80.43666666666667 , perteneciente a la provincia del Guayas. Las muestras se tomaron de forma aleatoria, considerando la coloración del agua, tomando 50 $\mathrm{mL}$ de muestra en tubos Corning ${ }^{\mathrm{TM}}$ Falcon $^{\mathrm{TM}}$ estériles. Posteriormente, se las guardó en una hielera a $4^{\circ} \mathrm{C}$ hasta procesarlas en el Laboratorio de la Facultad de Ciencias Naturales de la Universidad de Guayaquil.

\section{Fase de laboratorio}

Preparación de medio de cultivos

Se prepararon los siguientes medios de cultivos: Chlorophyta: BG11 (Allen, 1968; Andrade et al., 2009) y Cianobacteria: Zarrouk (1966) (Pineda et al., 2011). Los componentes de cada medio se presentan en el Anexo 1 y 2. Posteriormente, se ajustó BG11a pH 7.8 \% y Zarrouk a pH $9.9 \%$.

\section{Procesamiento y aislamiento de las muestras} Antes de realizar la siembra, se observó en el microscopio con el objetivo 40x y 100x para verificar 
la presencia de microorganismos fitoplanctónicos. Para el aislamiento de las cepas de microalgas y cianobacterias se emplearon los protocolos propuestos por Rippka (1988) y Waterbury (2006) de la siguiente forma: técnicas de separación física por agotamiento, estrías y extensión para medio sólido y diluciones seriadas para medio liquido (Andersen, 2005; Arredondo et al., 2007; García et al., 2017; Tenorio et al., 2018).

Para la técnica de agotamiento por estrías y extensión, se inoculó $20 \mu \mathrm{L}$ de la muestra en medios de cultivo sólidos BG11 para la Chlorophyta (Haneda et al., 2015) y Zarrouk (1966) para las Cyanobacteria, con el fin de aislar y purificar cultivos contaminados con varios microorganismos.

En el caso de microorganismos filamentosos se omitió este paso. Las condiciones de las cajas de Petri fueron temperatura ambiente, iluminación de lámparas fluorescentes a una intensidad baja de 10-75 $\mu \mathrm{mol} \mathrm{m} \mathrm{m}^{-2}$ $\mathrm{s}^{-1}$, fotoperiodo $16 \mathrm{~h}$ luz/8h oscuridad (16:8), durante un periodo de 8 días, de igual manera, se observaron en el microscopio y las colonias específicas se las transfirió en otra caja de Petri, consecutivamente, se replicó el proceso hasta que las cepas se encuentren puras (Arredondo et al., 2007; Chan et al., 2013; Waterbury, 2006).

El aislamiento en medio líquido se lo realizó mediante diluciones seriadas, primero, se inoculó biomasa de las cajas de Petri de las tres cepas mediante un aza de platino y se colocó en tubos de ensayo con $50 \mathrm{~mL}$ de medio BG11a pH 7.8 \% y Zarrouk a pH 9.9 \%. Luego de 10 días de incubación se realizó el aislamiento por diluciones $(1: 10,1: 100$ y $1: 1000)$ tomando $1 \mathrm{~mL}$ de la muestra original y se la agregó a un tubo de ensayo con $9 \mathrm{~mL}$ de medio de cultivo estéril y fresco, se homogenizó y así se repitió el proceso sucesivamente $\left(10^{-3}\right)$.

Posteriormente, se analizaron los aislados en el microscopio y las cepas que se encontraban puras se pasaron a matraces de $250 \mathrm{~mL}$ durante 7 días, con las siguientes condiciones: aireación constante, fotoperiodo (16:8); intensidad lumínica de $125 \mu \mathrm{mol}$ $\mathrm{m}^{-2} \mathrm{~s}^{-1}$ (proporcionada por lámparas fluorescentes FSL T8 $36 \mathrm{~W} / 865)$, y temperatura de $25 \pm 1{ }^{\circ} \mathrm{C}$. Este material servirá como fuente para la extracción posterior de ácidos nucleicos.

\section{Identificación y caracterización morfológica}

Para la identificación morfológica de las cepas se empleó un microscopio óptico con los objetivos 40x y $100 x$, subsiguientemente, se tomaron medidas taxonómicas (ancho y largo de las células) con ayuda del programa Digital Image System Software (Digital Imaging Systems ${ }^{\circledR}$, Buckinghamshire, England) y NISelements Documentation (NIKON Imaging Software ${ }^{\circledR}$ ).

Para la identificación y caracterización fenotípica de las especies fitoplanctónicas se utilizaron las claves taxonómicas de Fawley \& Fawley (2020), Johansen et al. (2011), Komárek et al. (2014), López-Osorio et al. (2011), Niiyama (2012), Rippka (1988), Wehr et al. (2015) y Wehr \& Sheath (2003).

\section{Densidad y crecimiento celular}

Se determinó la densidad celular durante 7 días mediante el recuento de células en el microscopio usando el hematocitómetro $0.1 \mathrm{~mm}$ de profundidad con reglilla de Neubauer, se empleó la fórmula propuesta por Bain (1998).

$$
C=N * 10^{4} * \text { dil }
$$

En donde:

$$
\begin{aligned}
& \mathrm{C}=\text { concentración celular expresada en cel } \\
& \mathrm{ML}^{-1} \text {. } \\
& \mathrm{N}=\text { promedio de células presentes. } \\
& \mathrm{Dil}=\text { factor de dilución. } \\
& 10^{4}=\text { factor de conversión de } 0.1 \mathrm{Ml} \text { a } 1 \mathrm{ML} .
\end{aligned}
$$

Para determinar el crecimiento celular se calcularon los datos de densidad celular en fase exponencial y se aplicó la ecuación planteada por Arredondo et al. (2007):

$$
\mu=\frac{\ln \left(N_{2}-N_{1}\right)}{t_{2}-t_{1}}
$$

En donde:

$$
N_{1} \text { y } N_{2} \text { : concentración en los tiempos } t_{1} \text { y } t_{2} \text {. }
$$

\section{Extracción y cuantificación de clorofila}

Según el método propuesto por Talling \& Driver (1961), para determinar el crecimiento relacionado con la concentración de clorofila a se tomó $2 \mathrm{ML}$ de muestra del cultivo por 7 días. Las alícuotas se centrifugaron por 25 minutos, $12000 \mathrm{rpm}$ a $4^{\circ} \mathrm{C}$ y se descartó el sobrenadante, se cubrió la totalidad del tubo eppendorf con papel de aluminio para evitar que la luz incida sobre la biomasa.

En la Sorbona de Extracción de Gases se añadió $2 \mathrm{ML}$ de acetona al 90 \% y se realizó vórtex por 5 minutos aproximadamente para el perfecto mezclado de los pellets de biomasa y el solvente. Posteriormente, se almacenó a $4{ }^{\circ} \mathrm{C}$ durante 24 horas.

Pasadas las 24 horas se centrifugó durante 25 minutos a $1200 \mathrm{rpm}$ para separar el pigmento disuelto en el solvente de los restos celulares, se observó el pellet totalmente blanquecino, lo cual, indicó la total extracción de los pigmentos liposolubles, en caso de realizar la extracción en cianobacterias el pellet podría observarse de color azul intenso o marrón (ficobiliproteínas). En caso de observarse el pellet de color verde, se deberá realizar vórtex nuevamente y esperar 24 horas a $4{ }^{\circ} \mathrm{C}$ para una perfecta extracción. Realizada la extracción se procedió a la lectura de la concentración pigmentaria mediante el MULTISKAN GO (Thermo Scientific). En la placa microtituladora se añadió $250 \mathrm{Ml}$ de acetona al $90 \%$, para realizar 
los blancos de las lecturas. En el MULTISKAN GO se escogió la opción de absorbancia y se ajustó a las nanometrías deseada, en este caso se realizaron dos nanometrías distintas ( $665 \mathrm{~nm}$ y $650 \mathrm{~nm})$.

La concentración de clorofila $a$ se obtiene a partir de las ecuaciones propuestas por Strickland \& Parsons (1972):

$$
C a(\mu g / m L)=16.5 A_{665}-8.3 A_{650}
$$

\section{Protocolo de extracción y purificación de ADN genómico}

El método CTAB (Hexadecyltrimethylammonium bromide) descrito por Doyle \& Doyle (1897) y modificado en el laboratorio se empleó para la extracción y purificación del ADN genómico total de las muestras. Estos métodos combinan una doble etapa de lisis mecánica y enzimática con una precipitación selectiva de CTAB, para superar los problemas de lisis y pureza que ocurren recurrentemente con las cianobacterias y microalgas.

Para la extracción total del ADN, las cepas se cultivaron en medio líquido durante 7 días (Yun et al., 2020). Cada una de las cepas se cosechó por centrifugación durante 5 minutos a $14000 \mathrm{rpm}$ a partir de $5 \mathrm{Ml}$ del medio líquido. Luego el buffer de lisis TES (Tris 100 Mm Ph 8, EDTA 10 Mm y SDS $10 \%$ ) se añadió y se sonicó (Biotech $4.3 \mathrm{TFT}$ ) a $4^{\circ} \mathrm{C}$ por 10 minutos a $20 \mathrm{kHz}$.

Después de sonicar, se agregó $12,56 \mathrm{Ml}$ de Proteinasa $\mathrm{K}\left(20 \mathrm{mg} \mathrm{Ml}^{-1}\right)$, y se incubó por 30 minutos a $37^{\circ} \mathrm{C}$ en el Thermomix. Luego se adicionó $140 \mathrm{Ml}$ de $\mathrm{NaCl}(5$ M) y $1 / 10$ volumen de CTAB al $10 \%$, y se lo colocó nuevamente en un baño termostático (Thermomix) durante 10 minutos a $65^{\circ} \mathrm{C}$. Posteriormente, se colocó 1 volumen de cloroformo: alcohol isoamílico (24:1) en hielo durante 5 minutos, seguidamente, se centrifugó a $14000 \mathrm{rpm}$ a $4{ }^{\circ} \mathrm{C}$.

El sobrenadante obtenido, se lo colocó en un nuevo tubo Eppendorf de $2 \mathrm{Ml}$, a continuación, se añadió 225 Ml de acetato de amonio (5 M) y nuevamente se lo colocó en hielo, y se lo llevó a centrifugar (10 min, $\left.4^{\circ} \mathrm{C}, 140000 \mathrm{rpm}\right)$. A continuación, al sobrenadante se le adicionó 5 volúmenes de isopropanol y se los llevó a $-20^{\circ} \mathrm{C}$ durante 30 min o 24 horas.

Posterior al tiempo establecido de congelación, las muestras se centrifugaron (20 $\left.\mathrm{min}, 4^{\circ} \mathrm{C} ; 14000 \mathrm{rpm}\right)$, se eliminó el sobrenadante y el pellet se lavó con 1 Ml de etanol al $70 \%$ y nuevamente se centrifugó (5 min, $4^{\circ} \mathrm{C}$; $14000 \mathrm{rpm}$ ), y se descartó una vez más el sobrenadante. El pellet se dejó secar durante 10 a 15 min dentro de la cámara de flujo laminar, con el objetivo de que el etanol al $70 \%$ se evapore. El ADN obtenido se resuspendió con $100 \mathrm{Ml}$ de agua ultra pura y se conservaron a $-20^{\circ} \mathrm{C}$ hasta su posterior uso.

\section{Cuantificación y calidad del ADN}

La concentración y pureza del ADN se obtuvo en base a las concentraciones en $\mathrm{ng} \mathrm{mL}^{-1}$ y valores de espectrofotometría según sus absorbancias $A_{260} / A_{280}$ $\mathrm{nm}$ y $\mathrm{A}_{260} / \mathrm{A}_{230} \mathrm{~nm}$, mediante el uso del NanoDrop (Thermo Scientific ${ }^{\mathrm{TM}}$ ).

Para cuantificar la concentración y calidad del ADN, se determinó un blanco, se empleó $2 \mathrm{Ml}$ de agua ultra pura empleada en la resuspensión del ADN, colocándola en el pedestal. Una vez determinado el blanco se colocó $2 \mathrm{Ml}$ de las muestras de extracción del ADN genómico.

Se definió la pureza mediante los rangos establecidos $\mathrm{A}_{260} / \mathrm{A}_{280} \mathrm{~nm}$ y $\mathrm{A}_{260} / \mathrm{A}_{230} \mathrm{~nm}$. Para el rango de absorbancia de $A_{260} / A_{280} n$, los valores 1.8 - 2.0 fueron considerados como ADN puro. Sin embargo, la pureza aceptable debe tener al menos una relación $\mathrm{A}_{260} / \mathrm{A}_{280} \mathrm{~nm}>1.6$, valores menores indican la presencia de contaminación de compuestos aromáticos como trazas de fenol y proteínas, y mayores $>2.1$ presencia de ARN en la muestra.

Los valores de 1.8-2.2 se consideran óptimos para el rango $A_{260} / A_{230} n m$ en relación a la pureza del $A D N$. Los valores menores $<1.8$ determinan la presencia de polisacáridos y polifenoles.

\section{Comprobación de la integridad del ADN por electroforesis}

La integridad del ADN genómico se la obtuvo mediante la técnica de electroforesis en gel de agarosa al $1 \%$ (p/v) con TBE 1X (Tris-HCl 45 Mm, Ph 8.0, EDTA 10 Mm, ácido bórico $45 \mathrm{Mm}$ ), teñido con $5 \mu$ SYBR Safe DNA Stain, a 55 Voltios por 30 minutos, con un marcador molecular de tamaño de 100 pb (Invitrogen).

En cada pocillo del gel se colocó $10 \mathrm{Ml}$ la siguiente mezcla: 9 Ml de ADNg y 1 Ml de Blue Juice ${ }^{T M}$ Gel Loading Buffer (10X), que es un tampón de carga, que permite visualizar las bandas de ADN. Finalmente, se observó como el ADN migró, ya que, la electroforesis separa los fragmentos de ADNg de acuerdo con su longitud en pb.

Si el ADN se encuentra íntegro, se deberá observar una banda estrecha próxima al pocillo donde se colocó la muestra de la extracción. Si el ADN se encuentra fragmentado se observará una banda de más de $1 \mathrm{~cm}$ de ancho o un camino luminoso en el carril de la muestra. El ADN fragmentado dificulta la amplificación de productos de PCR de alto peso molecular y afecta la reproducibilidad de las técnicas (Cornejo et al., 2015).

\section{Reacción en cadena de la polimerasa (PCR)}

La PCR es una de las herramientas moleculares más empleadas por diversas áreas científicas, principalmente en el área de microbiología y biología, debido a la especificidad de sus resultados (Cornejo et al., 2015).

Para confirmar la identidad de las cepas aisladas, se realizó PCR con diferentes parejas de cebadores. Se realizaron 3 reacciones de PCR por cada región a 
amplificar y un control negativo que no contenía ADN, además, por la especificidad de los mismos cebadores, se determinaron las condiciones de PCR.

\section{Condiciones de amplificación para PCR de la región de ADNr}

La amplificación de los fragmentos específicos de los genes del ADNr se lo realizó mediante Reacción en Cadena de la Polimerasa (PCR) empleando el protocolo de descrito por Kalendar et al. (2017)in silico or virtual (bioinformatics, que consistía en la preparación de una MasterMix que contenía lo siguiente: GoTaq ${ }^{\circledR}$ Green Master Mix (2X) (PROMEGA), que es una solución premezclada que incluía GoTaq ${ }^{\circledR}$ Reaction Buffer ( $\mathrm{pH}$ 8.5), GoTaq DNA Polymerase, $\mathrm{MgCl}_{2}$, dNTPs, y tampones de reacción a concentraciones óptimas para la amplificación eficiente de las plantillas de ADN por PCR, además, se le agregó los primers Forward y Reverse $(10 \mu \mathrm{M})$ y agua ultra pura, en un volumen total de $30 \mu \mathrm{L}$ (Tabla 1).

Mediante el uso del termociclador MultiGene ${ }^{\mathrm{TM}}$ OptiMax de Labnet se realizó la amplificación de las tres cepas en microtubos de $200 \mu \mathrm{L}, 3$ réplicas por cepa.

\section{Primers empleados}

Para los análisis de secuenciación del ADNg de las tres cepas aisladas de las piscinas de oxidación se emplearon ocho parejas de primers universales (Tabla 2).

\section{Región espaciadora interna 2 (ITS2)}

La región interna espaciadora 2 se amplificó usando los cebadores S2F Forwards (5'-ATG CGA TAC TTG GTG TGA AT-3') y S3R Reverse (5'- GAC GCT TCT CCA GAC TAC AAT -3') (Chen et al., 2010). La amplificación de la reacción en cadena de la polimerasa (PCR) de la región ITS2 se realizó en un volumen final de $30 \mu \mathrm{L}$. Las condiciones de PCR consistieron en una desnaturalización inicial durante 5 minutos a $94^{\circ} \mathrm{C}$; seguido de 40 ciclos de desnaturalización a $94^{\circ} \mathrm{C}$ durante 30 segundos, hibridación de $56^{\circ} \mathrm{C}$ durante 30 segundos y $72^{\circ} \mathrm{C}$ durante 45 segundos, seguido de $72^{\circ} \mathrm{C}$ de extensión final durante 5 minutos.

\section{Espaciador transcrito interno (ITS)}

Para la región ITS se utilizó los primers ITS1 Forwards (5'-TCCGTAGGTGAACCTGCGG-3') e ITS4 Reverse (5'-TCCTCCGCTTATTGATATGC-3') (White et al., 1990). Las amplificaciones de PCR se realizaron en un volumen final de $30 \mu \mathrm{L}$. Las condiciones de PCR consistieron en una desnaturalización inicial por 5 minutos a $95^{\circ} \mathrm{C} ; 35$ ciclos de desnaturalización por 40 segundos a $94^{\circ} \mathrm{C}$, hibridación durante 40 segundos a $58^{\circ} \mathrm{C}$ y extensión a $72^{\circ} \mathrm{C}$ por 40 segundos, con extensión final a $72^{\circ} \mathrm{C}$ por 5 minutos.

\section{Subunidad grande del ribosoma (LSU)}

La región de la subunidad grande del ribosoma (LSU) se utilizó los primers, LROR Forwards (5'-ACCCGCTGAACTTAAGC-3') y LR5 Reverse ( 1990)restriction digests, Southern blotting, and hybridization. We describe a novel approach that uses the polymerase chain reaction (PCR. Las amplificaciones de PCR se realizaron en un volumen final de $30 \mu \mathrm{L}$. Se emplearon las mismas condiciones de PCR que para la región ITS, con una variación en la etapa de hibridación a $59^{\circ} \mathrm{C}$ durante 30 segundos.

\section{Región de ARN ribosomal $16 \mathrm{~S}$}

La región $16 \mathrm{~S}$ ARNr es un componente de la subunidad pequeña del ribosoma procariota, se amplificó empleado los primers universales, $27 \mathrm{~F}$ Forwards (5'-AGAGTTTGATCCTGGCTCAG-3') y Reverse 1492R (5'-GGTTACCTTGTTACGACTT-3') (Turner et al., 1999). Las amplificaciones de PCR se realizaron en un volumen final de $30 \mu \mathrm{L}$. Las condiciones de PCR consistieron en una desnaturalización inicial durante $10 \mathrm{~min}$ a $95^{\circ} \mathrm{C}$; seguido de 35 ciclos de desnaturalización a $95^{\circ} \mathrm{C}$ durante 30 segundos, hibridación de $55^{\circ} \mathrm{C}$ durante 1 minuto y $72^{\circ} \mathrm{C}$ durante 2 minutos, seguido de $72{ }^{\circ} \mathrm{C}$ de extensión final durante $5 \mathrm{~min}$.

\section{Electroforesis}

Para comprobar la amplificación de los productos de PCR se realizó electroforesis en el gel de agarosa al $1,5 \%(p / v)$ en TBE 1X mediante el protocolo propuesto por Sambrook \& Russell (2001) y Yábar (2003). Se empleó $5 \mu \mathrm{L}$ de cada reacción de PCR, para determinar la presencia de amplicones (Morin et al., 2010). Para la observación de las bandas en el gel se empleó transiluminación con luz UV y el sistema de foto documentación Omega Fluor plus.

\section{Análisis bioinformáticos}

Para corroborar la identificación morfológica de las cepas, se realizó la secuenciación molecular y el posterior el análisis filogenético de la región del espaciador transcrito interno (ITS), el ARN de la subunidad grande del ribosoma (LSU), el espaciador transcrito interno 2 (ITS2) y, de la región ribosomal (16S RNAr).

Tabla 1. Composición y concentración de reactivos de la MasterMix para PCR con un volumen final de $30 \mu \mathrm{L}$ por reacción.

\begin{tabular}{ccc}
\hline Reactivo & Volumen por reacción & $\begin{array}{c}\text { Concentración } \\
\text { Volumen final }\end{array}$ \\
\hline GoTaq ${ }^{\circledR}$ Green Master Mix $(2 \mathrm{X})$ & $15 \mu \mathrm{L}$ & $1 \mathrm{X}$ \\
Primers forward $(10 \mu \mathrm{M})$ & $1.5 \mu \mathrm{L}$ & $0.1-1.0 \mu \mathrm{M}$ \\
Primers reverse $(10 \mu \mathrm{M})$ & $1.5 \mu \mathrm{L}$ & $0.1-1.0 \mu \mathrm{M}$ \\
H2O ultra pura & $11 \mu \mathrm{L}$ & $\mathrm{N} / \mathrm{A}$ \\
ADN genómico & $1 \mu \mathrm{L}$ & $<250 \mathrm{ng}$ \\
\hline
\end{tabular}


Tabla 2. Cebadores universales que amplificaron las regiones del ADNg de las cepas aisladas de microorganismos fitoplanctónicos obtenidos de las piscinas de oxidación de la comuna Engabao, provincia del Guayas, Ecuador.

\begin{tabular}{|c|c|c|c|c|c|}
\hline Primers & Secuencia (5’ a 3') & Locus & $\begin{array}{l}\text { Temperatura } \\
\text { de fusión } T_{m} \\
\quad\left(C^{\circ}\right)\end{array}$ & $\begin{array}{c}\text { Tamaño } \\
\text { amplicón } \\
\text { esperado } \\
\text { (pb) }\end{array}$ & Referencia \\
\hline S2F & ATG CGA TAC TTG GTG TGA AT & \multirow{2}{*}{ ITS2 } & $54.3^{\circ} \mathrm{C}$ & \multirow{2}{*}{$490-560$} & \multirow{2}{*}{ (Chen et al., 2010) } \\
\hline S3R & GAC GCT TCT CCA GAC TAC AAT & & $59.4^{\circ} \mathrm{C}$ & & \\
\hline ITS1 & TCC GTA GGT GAA CCT GCG G & \multirow{2}{*}{ ITS } & $65^{\circ} \mathrm{C}$ & \multirow{2}{*}{$500-750$} & \multirow{2}{*}{ (White et al., 1990) } \\
\hline ITS4 & TCC GCT TAT TGA TAT GC & & $58^{\circ} \mathrm{C}$ & & \\
\hline LROR & ACC CGC TGA ACT TAA GC & \multirow{2}{*}{ LSU } & $51.1^{\circ} \mathrm{C}$ & \multirow{2}{*}{$1200-1500$} & \multirow{2}{*}{ (Vilgalys \& Hester, 1990) } \\
\hline LR5 & TCC TGA GGG AAA CTT CG & & $50.6^{\circ} \mathrm{C}$ & & \\
\hline $27 \mathrm{~F}$ & AGA GTT TGAT CCT GGC TCAG & \multirow{2}{*}{$16 \mathrm{~S}$} & $56^{\circ} \mathrm{C}$ & \multirow{2}{*}{$1000-1500$} & \multirow{2}{*}{ (Turner et al., 1999) } \\
\hline $1429 R$ & GGT TAC CTT GTT ACG ACTT & & $55.4^{\circ} \mathrm{C}$ & & \\
\hline
\end{tabular}

\section{Secuenciación genómica}

Los productos de PCR de las muestras aisladas y purificadas con un volumen final de $25 \mathrm{~mL}$ se colocaron en tubos Eppendorf de $1.5 \mathrm{~mL}$, se rotularon y sellaron con Parafilm, posteriormente, se enviaron por el sistema de paquetería FedEx en avión a Macrogen, Rockville, MD, USA. Las condiciones del paquete fueron a temperatura ambiente. Los análisis bioinformáticos se los realizó mediante MEGAX según Kumar et al. (2018).

Las secuencias obtenidas de los diferentes cebadores, se analizaron individualmente; primero, se compararon con la base de nucleótidos de GenBank de la plataforma "National Center for Biotechnology Information” (NCBI) (https://www.ncbi.nlm.nih. gov/) para establecer la homología entre ambas secuencias (Kazi et al., 2013).

Posteriormente, mediante el uso del algoritmo "Basic Local Alignment Search Tool Nucleotide" (BLASTn) (https://blast.ncbi.nlm.nih.gov/Blast.cgi) y el del software "Molecular Evolutionary Genetics Analysis" (MEGAX) (https://www.megasoftware.net/) se procesaron las secuencias, se cortaron y se alinearon manualmente para ensamblar las secuencias consenso de cada pareja de primers empleando la herramienta MUSCLE. Para determinar la identidad y similitud de las secuencias conceso de cada cepa se empleó BLASTn de la base de datos "Nucleotide collection (nr/nt)" del NCBI (http://blast.ncbi.nlm.nih.gov/ Blast.cgi) (Madden, 2012).

\section{Análisis filogenéticos}

Para la construcción de los árboles filogenéticos se empleó las secuencias consenso de las tres especies de microrganismos fitoplanctónicos, junto a secuencias de material tipo de especies registradas del NCBI. Las reconstrucciones filogenéticas se realizaron mediante el método algorítmico de Máxima Probabilidad (Maximun Likelihood, ML), que calcula las distancias genéticas mediante un modelo de sustitución tipo nucleótido, con el soporte Bootstrap (técnica estadística que genera un número elevado de pseudoréplicas del alineamiento original) con 1000 repeticiones para comprobar la máxima verosimilitud de todas las ramas (clados) producidas, utilizando el software Mega X (Kumar et al., 2018).

\section{Resultados}

Aislamiento, purificación e identificación Se obtuvo un total de tres cepas aisladas de microorganismos fitoplanctónicos de muestras obtenidas de las piscinas de oxidación: una microalga y dos cianobacterias, con medios de cultivo y $\mathrm{pH}$ óptimo, los cuales son mostrados en la Tabla 3. Los tres microorganismos aislados se identificaron a través de diversas claves taxonómicas: Fawley \& Fawley (2020), Johansen et al. (2011), Komárek et al. (2014), LópezOsorio et al. (2011), Niiyama (2012), Rippka (1988), Wehr et al. (2015) y Wehr \& Sheath (2003), en los que se describieron las siguientes especies:

\section{Cepa Chl1 - Chlorella sorokiniana}

Es una especie de microalga inmóvil, unicelular, solitaria, con morfología esférica, coloración verde esmeralda, células de 2 a $10 \mu \mathrm{m}$ de diámetro, sin pared celular lisa, no presentan constricción en la parte media, cloroplasto en forma parietal con un pirenoide, y carece de flagelo, característica común en la familia Chlorellaceae (Luo et al., 2010; Wehr \& Sheath, 2003)the concept of the experimental

Tabla 3. Muestras aisladas en medios de cultivo y pH óptimos.

\begin{tabular}{cccc}
\hline Cepa & Nombre científico & $\begin{array}{c}\text { Medio de } \\
\text { cultivo }\end{array}$ & $\mathrm{pH}$ \\
\hline Chls1 & $\begin{array}{c}\text { Chlorella sorokiniana } \\
\text { Syn1 }\end{array}$ & BG11 & 7.8 \\
Nod1 & $\begin{array}{c}\text { Nodosilinea sp. } \\
\text { Nococcus sp. }\end{array}$ & Zarrouk & 9.9 \\
\hline
\end{tabular}




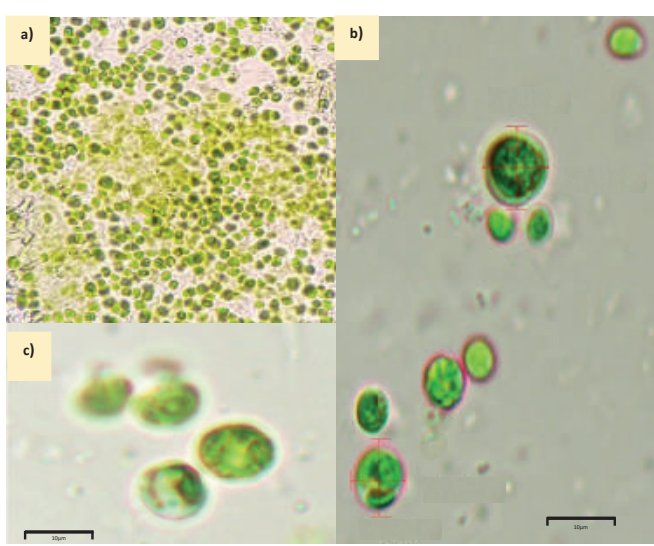

Figura 1. a) Cepa Chls1 (Chlorella sorokiniana) aislada de las piscinas de oxidación de la Comuna Engabao; objetivo 40x. b, c) Medición del diámetro de la célula mediante el uso del programa NIS-elements Documentation (NIKON Imaging Software $\left.{ }^{\circledR}\right)$; objetivo 100x.

algal genus Chlorella was evaluated. Conventionally in the genus Chlorella, only coccoid, solitary algae with spherical morphology that do not possess any mucilaginous envelope were included. All Chlorella species reproduce asexually by autospores. However, phylogenetic analyses showed that within the clade of 'true'. Chlorella species (Chlorella vulgaris, C. lobophora, and C. sorokiniana, además, sus colonias se encuentran rodeadas de mucílago y la modalidad de la agregación de la célula es característica de las especies lo que facilita su identificación (Fig. 1; Moronta et al., 2006; Shihira \& Krauss, 1965).

\section{Cepa Syn2 - Synechococcus sp.}

Pertenece al género de cianobacterias unicelulares cocales (Nägeli, 1849), son solitarias o formando en colonias microscópicas o macroscópicas irregulares sin mucílago común. Las células son de forma oval y redondeadas en los extremos, sin embargo, pueden ser más largas que anchas o viceversa, arqueadas, rectas o incluso sigmoideas, miden alrededor de 3.57 $\pm 0.12 \mu \mathrm{m}$ de longitud y $1.47 \pm 0.09 \mu \mathrm{m}$ de ancho, coloración azul verdoso pálido. Presentan un mucílago delgado o ausente, incoloro, homogéneo alrededor de las células (Fig. 2) (Komárek et al., 2014; Rosales et al., 2005; Wehr \& Sheath, 2003)we test the small molecule flexible ligand docking program Glide on a set of 19 non-a-helical peptides and systematically improve pose prediction accuracy by enhancing Glide sampling for flexible polypeptides. In addition, scoring of the poses was improved by post-processing with physicsbased implicit solvent MM- GBSA calculations. Using the best RMSD among the top 10 scoring poses as a metric, the success rate (RMSD $\leq 2.0 \AA$ for the interface backbone atoms.

\section{Cepa Nod3 - Nodosilinea sp}

Es una cianobacteria que presenta filamentos verdes

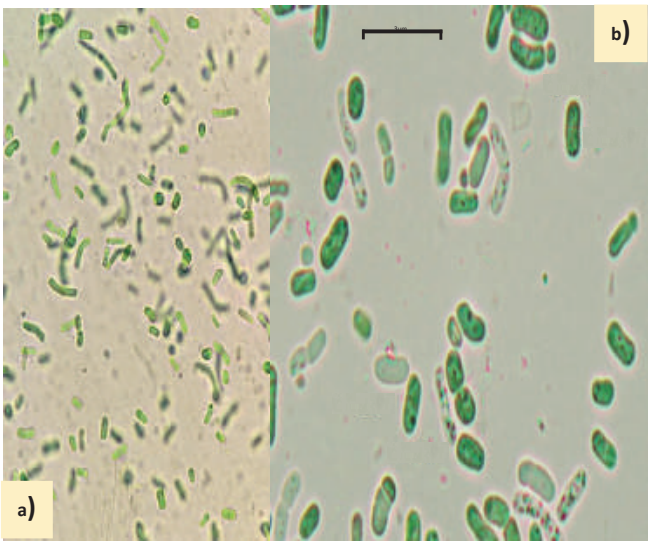

Figura 2. a) Cepa Syn2 (Synechococcus sp.) aislada en el Laboratorio de la Facultad de CCNN a partir de muestras de las piscinas de oxidación de la Comuna Engabao; objetivo 100x. b) Medición de la célula (largo y ancho) mediante el uso del programa NIS-elements Documentation (NIKON Imaging Software $\left.{ }^{\circledR}\right)$; objetivo 100x.

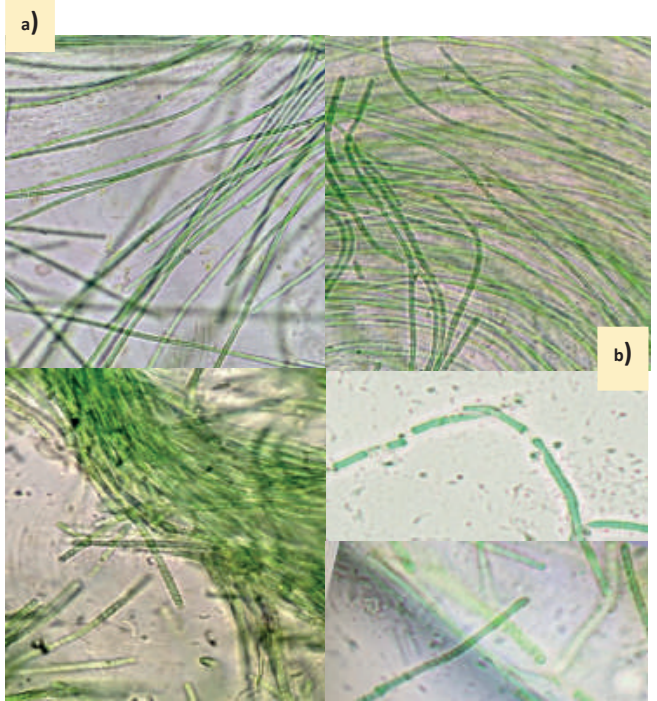

Figura 3. a) Cepa Nod1 (Nodosilinea sp.) aislada en el Laboratorio de la Facultad de CCNN a partir de muestras de las piscinas de oxidación de la comuna Engabao; objetivo 100x. b) Observación de los segmentos del filamento y la parte apical mediante el uso del programa NIS-elements Documentation (NIKON Imaging Software ${ }^{\circledR}$ ); objetivo 40x 100x.

y delgados de aproximadamente de 1.1 a $1.3 \mu \mathrm{m}$ de ancho, pueden poseer alrededor de más de 350 células de largo, además poseen forma de barril y sus extremos son redondeados (Johansen et al., 2011; Niiyama, 2012; Fig. 3.).

\section{Cinética de crecimiento}

El cultivo de C. sorokiniana a los siete días de cultivo mostró una densidad máxima de $25.4 \times 10^{6} \pm 8.94$ 
Rev. Cient. Cien. Nat. Ambien. 15(2):259-277

Diciembre 2021
Cabrera, et al • Aislamiento y caracterización molecular de cepas fitoplanctónicas obtenidas en Engabao, Guayas-Ecuador $\mathrm{x} 10^{5}$ cel $\mathrm{mL}^{-1}$ y una velocidad de crecimiento $(\mu)$ de $0.19 \pm 0.03 \mathrm{~d}^{-1}$ (fig. 4).

Mientras que Synechococcus sp. presentó una densidad máxima de $340.6 \pm 5.9 \times 10^{6} \mathrm{cel} \mathrm{mL}^{-1}$ y una velocidad de crecimiento $(\mu)$ de $0.20 \pm 0,02 \mathrm{~d}^{-1}$ (Fig. 5).

Crecimiento celular de Nodosilinea sp. mediante el análisis de clorofila $a$ con $6,33 \mu \mathrm{g} \mathrm{mL}^{-1}$ en un periodo de siete días (Fig. 6).

\section{Análisis molecular}

Extracción, concentración y calidad del ADN genómico

El material genético se lo obtuvo mediante el protocolo de extracción y purificación de ADNg estandarizado y modificado. Para cada cepa se empleó $5 \mathrm{~mL}$ de cultivo

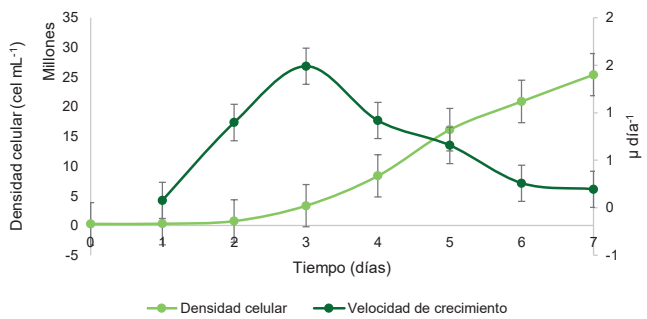

Figura 4. Densidad celular y velocidad de crecimiento de Chlorella sorokiniana durante siete días de cultivo.

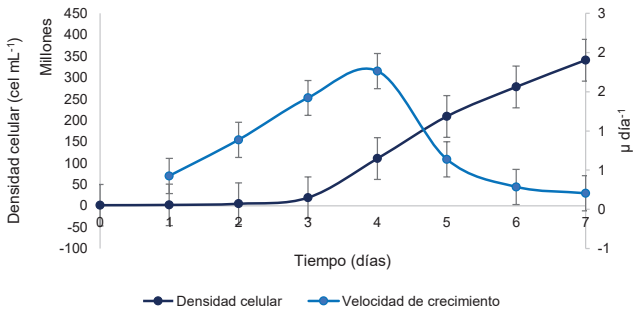

Figura 5. Densidad celular y velocidad de crecimiento de Synechococcus sp. durante siete días de cultivo.

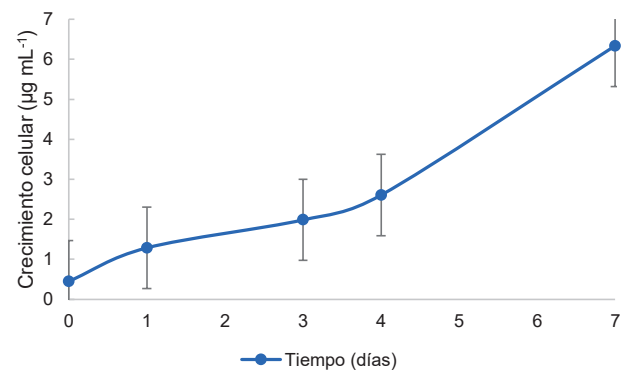

Figura 6. Crecimiento celular de Nodosilinea sp. durante siete días de cultivo mediante análisis de clorofila a. en fase logarítmica con 7 días de crecimiento celular. Se cuantificó la concentración y calidad del ADN genómico total mediante el uso de espectrofotometría (NanoDrop Thermo Scientific ${ }^{\mathrm{TM}}$ ), demostrando que la pureza del ADN y las concentraciones eran altas en las tres especies de microorganismos fitoplanctónicos (Tabla 4.).

El análisis de electroforesis en gel de agarosa al 1\% demostró la detección de bandas de ADN íntegro, que no posee contaminantes tales como proteínas y polisacáridos. El ADN genómico extraído de las tres cepas no se encuentra degradado (Fig. 7), por consiguiente, se observa en los carriles 1, 2 y 3 una banda intensa y única, mientras que marcador molecular es la banda de mayor tamaño de 100 pb.

\section{PCR}

Amplificación de los productos de PCR

Se emplearon 4 parejas de cebadores universales, para la amplificación y secuenciación de $C$. sorokiniana, se empleó el ITS2, ITS y LSU con condiciones de reacción establecidas anteriormente, mientras que, para las dos cianobacterias aisladas: Synechococcus sp. y Nodosilinea sp., se analizó la región del 16S RNAr. Para determinar la amplificación de los productos de PCR se realizó electroforesis en gel de agarosa al $1.5 \%$.

\section{Amplificación por PCR de la región ITS2}

La amplificación por PCR de la región ITS con los cebadores S2F y S3R dio como resultado una banda de $\sim 600$ pb. El fragmento se obtuvo de la cepa Chlorella sorokiniana (Fig. 8).

\section{Amplificación por PCR de la región ITS}

La amplificación por PCR de la región ITS con los cebadores ITS1 e ITS4 dio como resultado una banda pb de $700 \mathrm{pb}$. El fragmento se obtuvo de la cepa Chlorella sorokiniana (Fig. 9).

\section{Amplificación por PCR de la región LSU}

La amplificación por PCR de la región LSU con los cebadores LROR y LR5 dio como resultado una banda de $\sim 1000 \mathrm{pb}$. El fragmento se obtuvo de la cepa Chlorella sorokiniana (Fig. 10).

\section{Amplificación por PCR de las regiones 16S RNAr} La amplificación por PCR de la región 16S RNAr con los cebadores $27 \mathrm{~F}$ y $1492 \mathrm{R}$ dio como resultado una banda de $~ 1200 \mathrm{pb}$. El fragmento se obtuvo de la cepa Synechococcus sp. (Fig. 11).

\section{Amplificación por PCR de las regiones 16S RNAr}

La amplificación por PCR de la región 16S RNAr con los cebadores $27 \mathrm{~F}$ y $1492 \mathrm{R}$ dio como resultado una banda de $1200 \mathrm{pb}$. El fragmento se obtuvo de la cepa Nodosilinea sp. (Fig. 12).

\section{Análisis bioinformático}

\section{Análisis molecular}

Las secuencias obtenidas por Macrogen-USA fueron procesadas por el software bioinformático MEGA X, obteniendo las secuencias consenso de las tres cepas, 
Tabla 4. Concentración de ADNg de las tres cepas aisladas de microorganismos fitoplanctónicos mediante la extracción de ADNg con método estándar en $\mathrm{ng} \mathrm{uL}^{-1}$ a partir de la relación de las absorbancias (CONC. = concentración).

\begin{tabular}{ccccc}
\hline Cepas aisladas & Densidad Celular & $\begin{array}{c}\text { CONC. de ADN } \\
(\mathrm{ng} \mathrm{mL}-1)\end{array}$ & \multicolumn{2}{c}{$\begin{array}{c}\text { Medición } \\
\text { Espectrofotométrica }\end{array}$} \\
\hline & & & $\begin{array}{c}\text { Relación } \mathrm{A}_{260} / \\
\mathrm{A}_{280}\end{array}$ & $\begin{array}{c}\text { Relación } \mathrm{A}_{260}{ }^{\prime} \\
\mathrm{A}_{230}\end{array}$ \\
\cline { 3 - 5 } Chlorella sorokiniana & $\begin{array}{c}25.4 \times 10^{6} \pm 8.94 \times 10^{5} \mathrm{cel} \\
\mathrm{mL}^{-1}\end{array}$ & 146 & 1.94 & 1.98 \\
Synechococcus sp. & $\begin{array}{c}340.6 \pm 5.9 \times 10^{6} \mathrm{cel} \mathrm{mL}^{-1} \\
\text { Nodosilinea sp. }\end{array}$ & 326 & 2.06 & 2.09 \\
\hline
\end{tabular}

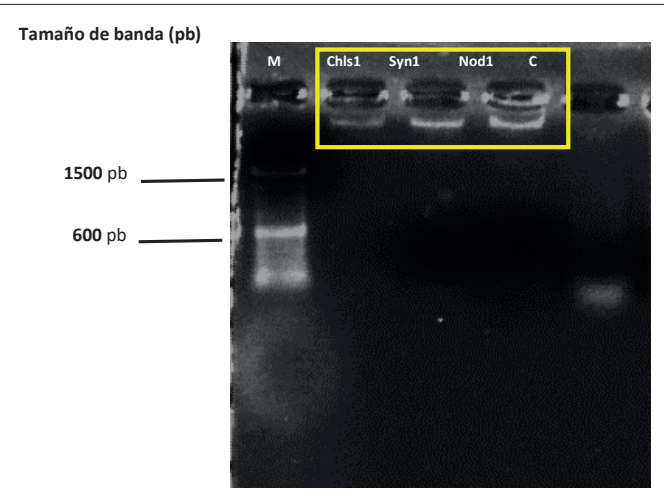

Figura 7. Electroforesis en gel de agarosa-TBE al 1\%, los carriles son las cepas Chls1 (Chlorella sorokiniana), Syn1 (Synechococcus sp.) y Nod1 (Nodosilinea sp.) pertenecientes a la extracción ADNg (rectángulo amarillo), C (control negativo), $M$ (marcador molecular).

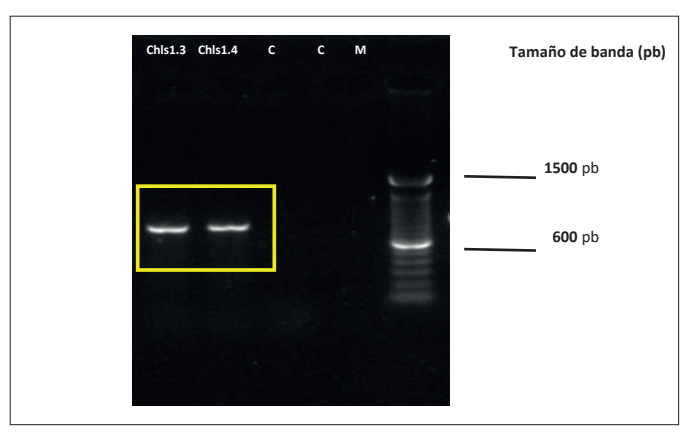

Figura 9. Amplificación de la región ITS para la cepa aislada Chls1 con los cebadores universales ITS1 e ITS4. Banda aproximadamente con $700 \mathrm{pb}$. Electroforesis en gel de agarosa-TBE al 1\%, los carriles Chls1.3 y Chls1.4 son réplicas de los productos de PCR (rectángulo amarillo), C (control negativo), $M$ (marcador molecular).

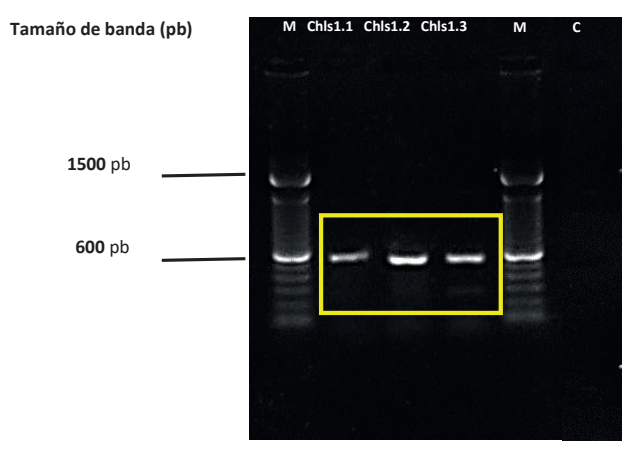

Figura 8. Amplificación de la región ITS2 para la cepa aislada Chls1 con los cebadores universales S2F y S3R. Banda aproximadamente con $600 \mathrm{pb}$. Electroforesis en gel de agarosa-TBE al 1\%, los carriles Chls1.1, Chls1.2 y Chls 1.3 son réplicas de los productos de PCR (rectángulo amarillo), C (control negativo), M (marcador molecular).

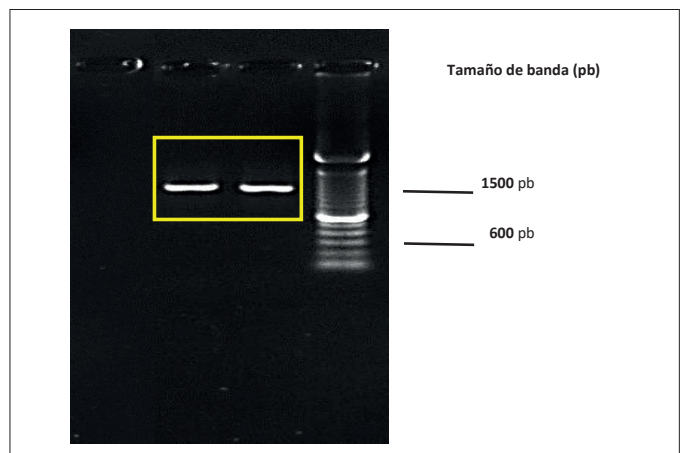

Figura 10. Amplificación de la región LSU para la cepa aislada Chls1 con los cebadores universales LROR y LR5. Banda aproximadamente con $1000 \mathrm{pb}$. Electroforesis en gel de agarosa- TBE al 1\%, los carriles Chls1.5 y Chls 1.6 son réplicas de los productos de PCR (rectángulo amarillo), C (control negativo), $M$ (marcador molecular). 


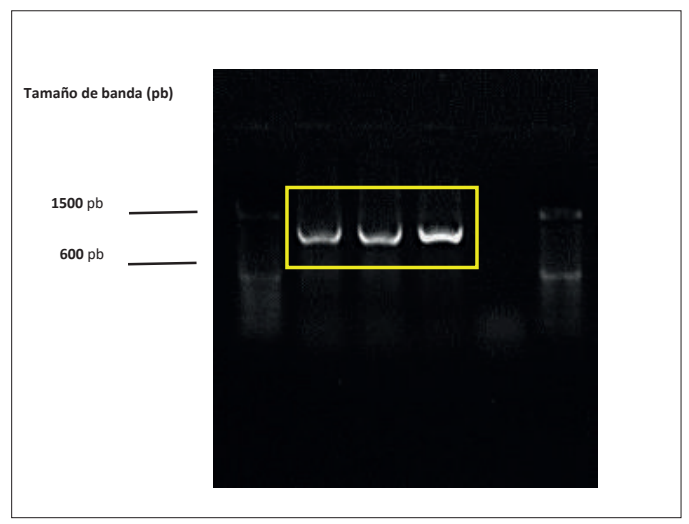

Figura 11. Amplificación de la región $16 \mathrm{~S}$ RNAr para la cepa aislada Syn1 con los cebadores universales $27 \mathrm{~F}$ y $1429 \mathrm{R}$. Banda aproximadamente con $1200 \mathrm{pb}$. Electroforesis en gel de agarosa- TBE al 1\%, los carriles Syn1.1 a Syn1.3 son réplicas de los productos de PCR (rectángulo amarillo), C (control negativo), $M$ (marcador molecular).

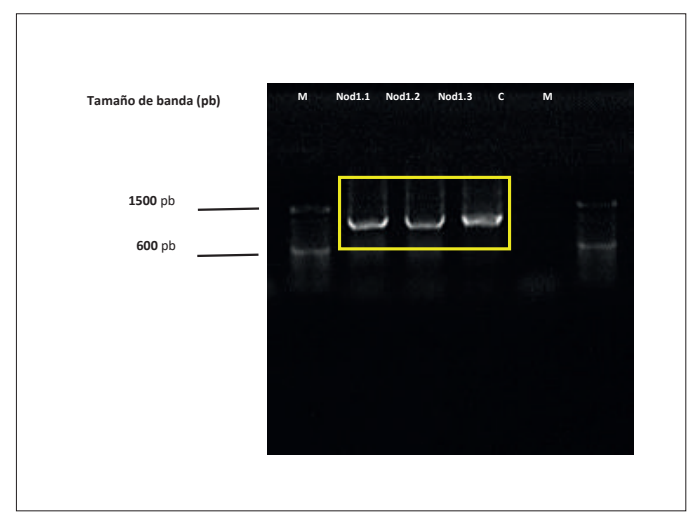

Figura 12. Amplificación de la región $16 \mathrm{~S}$ RNAr para la cepa aislada Nod1 con los cebadores universales 27F y $1429 R$. Banda aproximadamente con 1200 pb. Electroforesis en gel de agarosa- TBE al 1\%, los carriles Nod1.1 a Nod1.3 son réplicas de los productos de PCR, C (control negativo), M (marcador molecular).

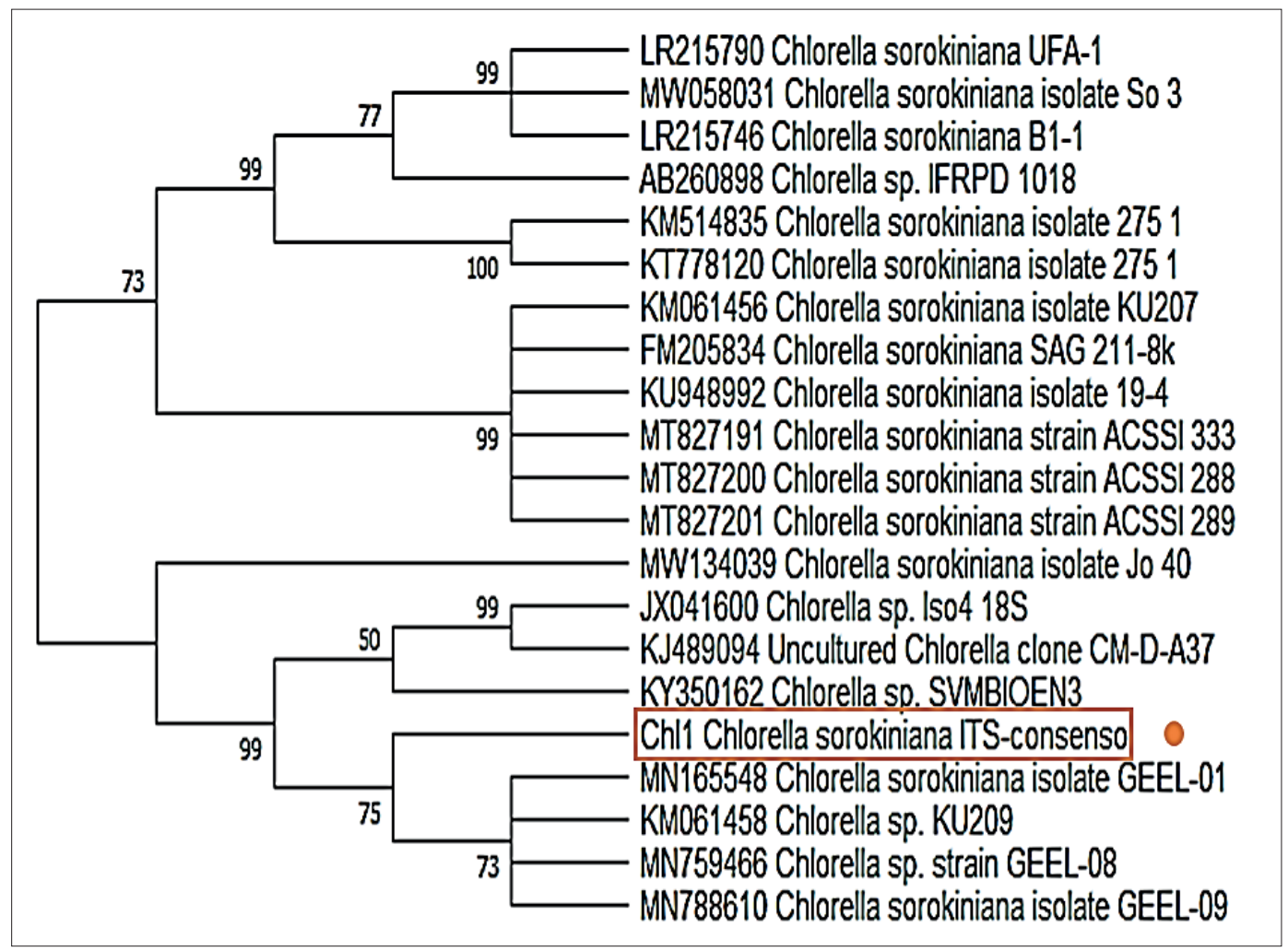

Figura 13. Dendrograma de agrupamiento para la muestra amplificada de la región ITS, en las piscinas de oxidación de la Comuna Engabao, Guayas. Método de agrupamiento por Máxima Verosimilitud (Maximum-likelihood), modelo de sustitución Tamura-Nei $(\mathrm{TN} 93+\mathrm{I}+\mathrm{G})$ y aproximación de Bootstrapping de 1000 permutaciones. La cepa aislada en este estudio se representa como $\mathrm{Chl} 1 \mathrm{Chlorella} \mathrm{sorokiniana} \mathrm{ITS-consenso.}$ 
Tabla 5. Secuencias del ADNr (ITS2, ITS, LSU y 16 S RNAr), utilizadas en los análisis filogenéticos, porcentajes de similitud y los números de acceso de GenBank.

\begin{tabular}{|c|c|c|c|c|}
\hline & & $\begin{array}{c}\text { Synechococcus sp. } \\
\text { Syn1 }\end{array}$ & $\begin{array}{c}\text { Nodosilinea sp. } \\
\text { Nod1 }\end{array}$ & $\begin{array}{c}\text { Chlorella } \\
\text { sorokiniana } \\
\text { Chls1 }\end{array}$ \\
\hline \multirow{3}{*}{ 16S RNAr } & E value & 0.0 & & \\
\hline & $\%$ similitud & $97,47 \%$ & & \\
\hline & \# accesión & KF912974 & & \\
\hline \multirow{3}{*}{ 16S RNAr } & E value & & 0.0 & \\
\hline & $\%$ similitud & & $99,83 \%$ & \\
\hline & \# accesión & & DQ085091 & \\
\hline \multirow{3}{*}{ ITS2 } & E value & & & 0.0 \\
\hline & $\%$ similitud & & & $99,48 \%$ \\
\hline & \# accesión & & & MN788610 \\
\hline \multirow{3}{*}{ ITS } & E value & & & 0.0 \\
\hline & $\%$ similitud & & & $99,07 \%$ \\
\hline & \# accesión & & & MN165548 \\
\hline \multirow{3}{*}{ LSU } & E value & & & 0.0 \\
\hline & $\%$ similitud & & & $99,77 \%$ \\
\hline & \# accesión & & & $\begin{array}{l}\text { FR751191 } \\
\text { Micractinium } \\
\text { reisseri }\end{array}$ \\
\hline
\end{tabular}

con las que se realizó el análisis de similitud mediante la herramienta BLASTn de la base de datos del NCBI. La identificación molecular de la cepa aislada Chls1, secuenciada con los genes del espaciador transcrito interno 2 (ITS2), el espaciador transcrito interno (ITS), el ARN de la subunidad grande del ribosoma (LSU) y alineada mediante análisis BLASTn coincidió con la identidad morfológica establecida anteriormente llegando a nivel de género y especie. Las parejas de primers universales ITS2 y ITS presentaron un porcentaje de similitud del $99,48 \%$, y $99,07 \%$ respectivamente con Chlorella sorokiniana, mientras que el primer LSU presentó un porcentaje de similitud de $99,77 \%$ con Micractinium reisseri (Tabla 5).

El análisis BLAST mostró que sus identidades moleculares de la región 16S RNAr eran consistentes con las identidades morfológicas de la cepa aislada Syn2, presentando un porcentaje de similitud del 97,47\% con Synechococcus sp. (Tabla 4). Igualmente, la cepa aislada Nod3 se logró identificar morfológica y genéticamente mediante el uso del marcador molecular de la región 16S RNAr con un el 99,83\% de similitud con Nodosilinea sp. (Tabla 5).

La homología de los resultados obtenidos de las secuencias con las asociadas en el GenBank secundó la elaboración de análisis filogenéticos de cada región empleada de los tres microorganismos fitoplanctónicos.

\section{Análisis filogenético}

El uso de análisis filogenéticos permitió obtener una mayor confiabilidad en la identificación de las cepas aisladas de microorganismos fitoplanctónicos mediante las secuencias parciales de las regiones ITS2, ITS, LSU y de la región 16S RNAr, de tal forma, demostrando que estos pertenecen a la identificación presuntiva basada en caracteres fenotípicos. Se observa en la topología de árbol los aislados: Chls1 (Chlorella sorokiniana), Syn1 (Synechococcus sp.) y Nod1 (Nodosilinea sp.).

Se ha construido un árbol filogenético (fig. 13) con la secuencia consenso de la región ITS de Chlorella sorokiniana, comprobando la identificación taxonómica de la cepa con 75\% Bootstrap (circulo naranja), compartiendo clado y secuencia genómica con otras especies de Chlorella. Los valores de probabilidad Bootstrap $>75 \%$ indican mayor fiabilidad. Para la construcción del siguiente árbol filogenético no se logró seleccionar un organismo que actuará como grupo externo debido a que la topografía de los árboles se vio afectada. 
El árbol filogenético (Fig. 14) basado la secuencia consenso de la región ITS2 de Chlorella sorokiniana (Chl1), presenta identificación taxonómica con 96\% Bootstrap (círculo naranja), compartiendo clado y secuencia genómica con otras especies del mundo. Se agregó 4 grupos externos de microorganismos que no pertenecen al grupo analizado, debido a que estos proporcionan información en relación a los caracteres ancestrales

En el análisis filogenético de la secuencia consenso de la región LSU (Fig. 15), se agrupó en el clado de las especies Micractinium reisseri y Cocomyxa sp., presentando ramas separadas $(99 \%, 79 \%$ y $100 \%$ bootstrap). Comprobando la identificación taxonómica de la cepa con $75 \%$ Bootstrap (círculo naranja). Los valores de probabilidad Bootstrap > 75 $\%$ indican mayor fiabilidad. Para la construcción del siguiente árbol filogenético no se logró seleccionar un organismo que actuará como grupo externo debido a que la topografía de los árboles se vio afectada.

El árbol filogenético de la secuencia consenso de la región 16S RNAr de Synechococcus sp. evidenció la identificación taxonómica de la cepa con 78\% Bootstrap (círculo naranja). Todas las especies del NCBI comparte más del $50 \%$ de similitud con la Syn1. aislada de la comuna Engabao (Fig. 16).

Según el análisis filogenético utilizando secuencias de la región ARNr 16S, Nodosilinea sp. está más relacionada con Leptolyngbya sp. OBB32S02, con

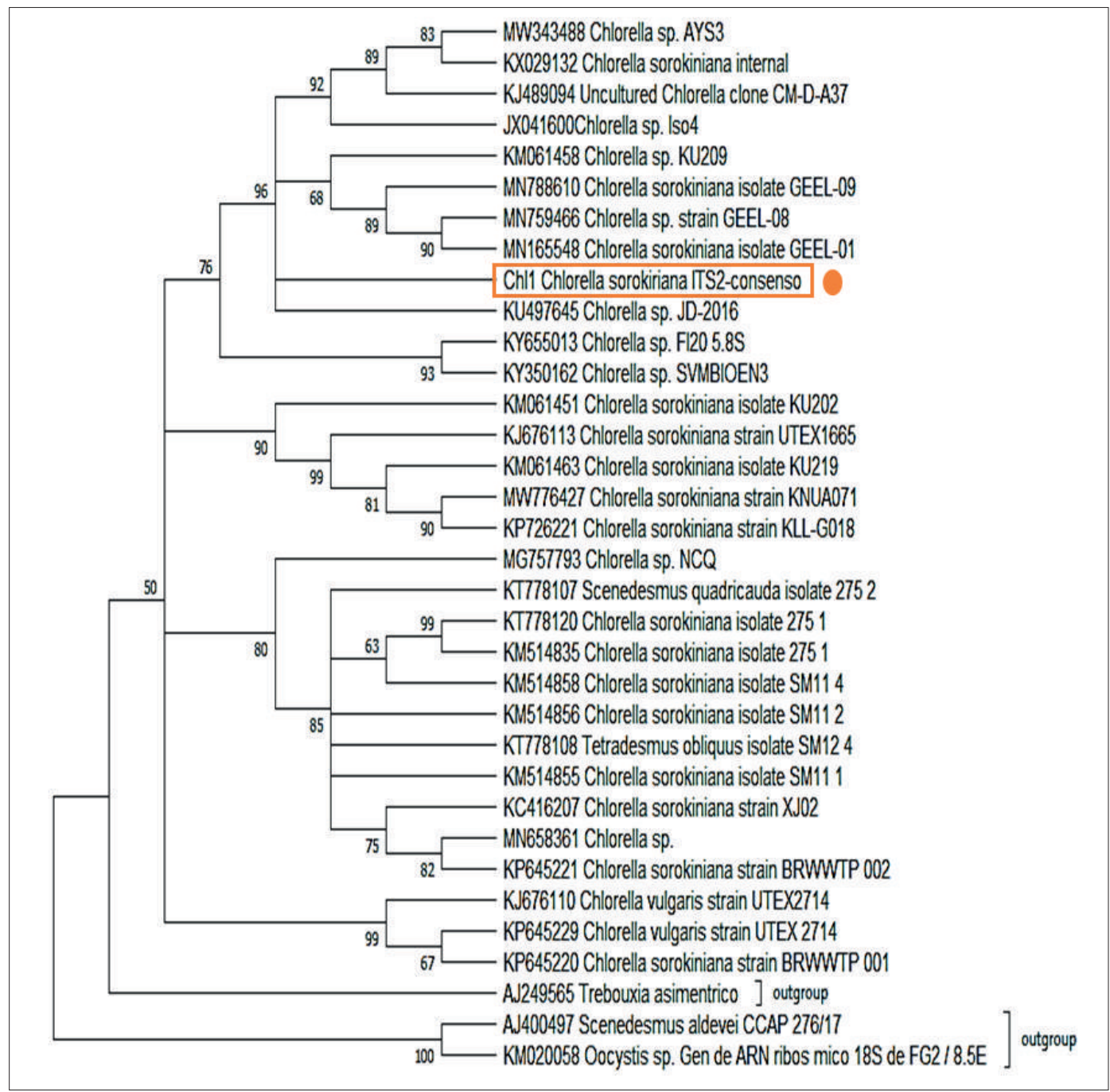

Figura 14. Dendrograma de agrupamiento para la muestra amplificada de la región ITS, en las piscinas de oxidación de la Comuna Engabao, Guayas. Método de agrupamiento por Máxima Verosimilitud (Maximum-likelihood), modelo de sustitución Tamura-Nei $(\mathrm{TN} 93+$ I + G) y aproximación de Bootstrapping de 1000 permutaciones. La cepa aislada en este estudio se representa como Chl1 Chlorella sorokiniana ITS2-consenso. 


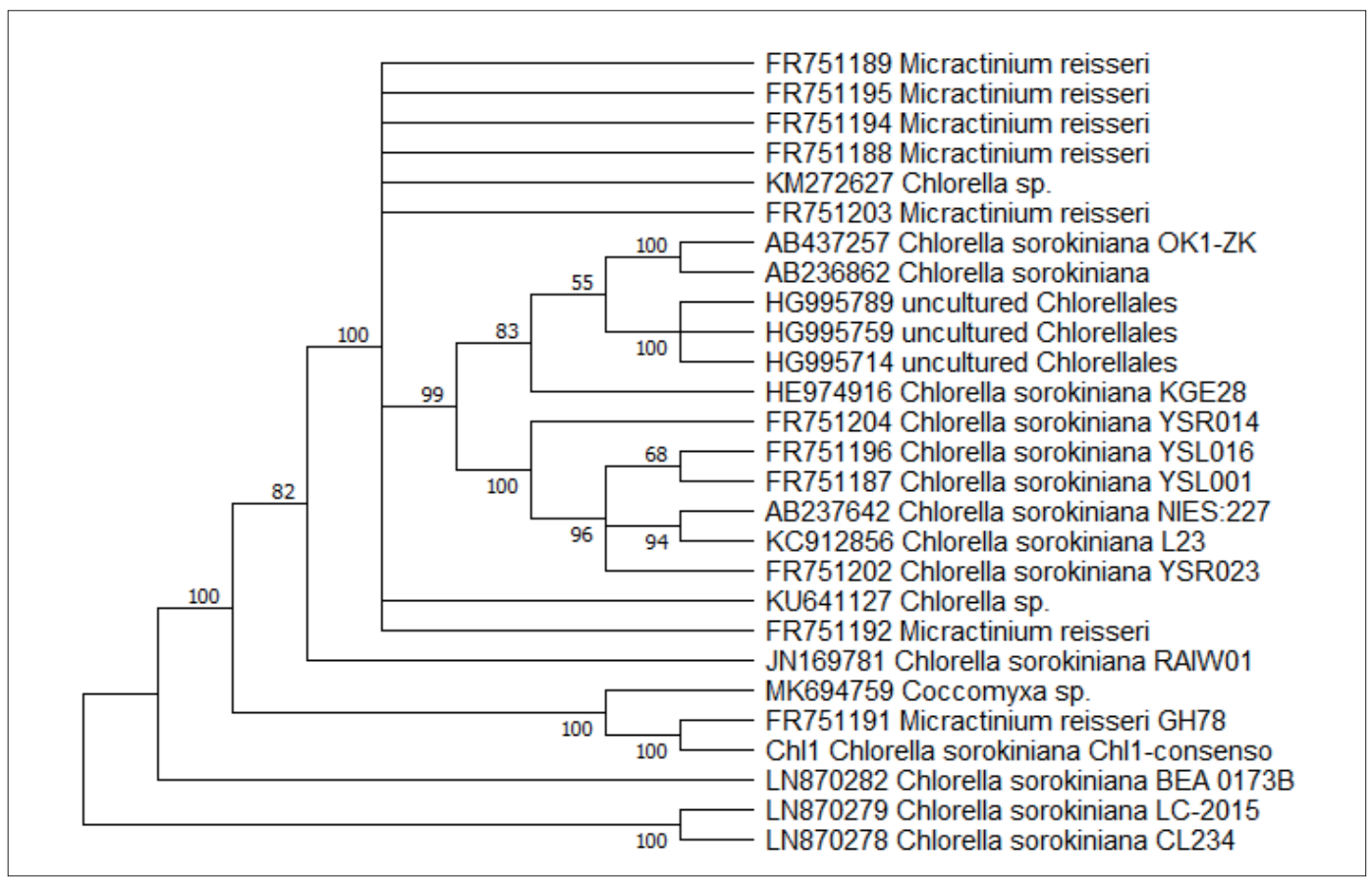

Figura 15. Dendrograma de agrupamiento para la muestra amplificada de la región LSU, en las piscinas de oxidación de la comuna Engabao, Guayas. Método de agrupamiento por Máxima Verosimilitud (Maximum-likelihood), modelo de sustitución Kimura 2 parámetros $(\mathrm{K} 2+\mathrm{G})$ y aproximación de Bootstrapping de 1000 permutaciones. La cepa aislada en este estudio se representa como Chl1 Chlorella sorokiniana LSU-consenso.

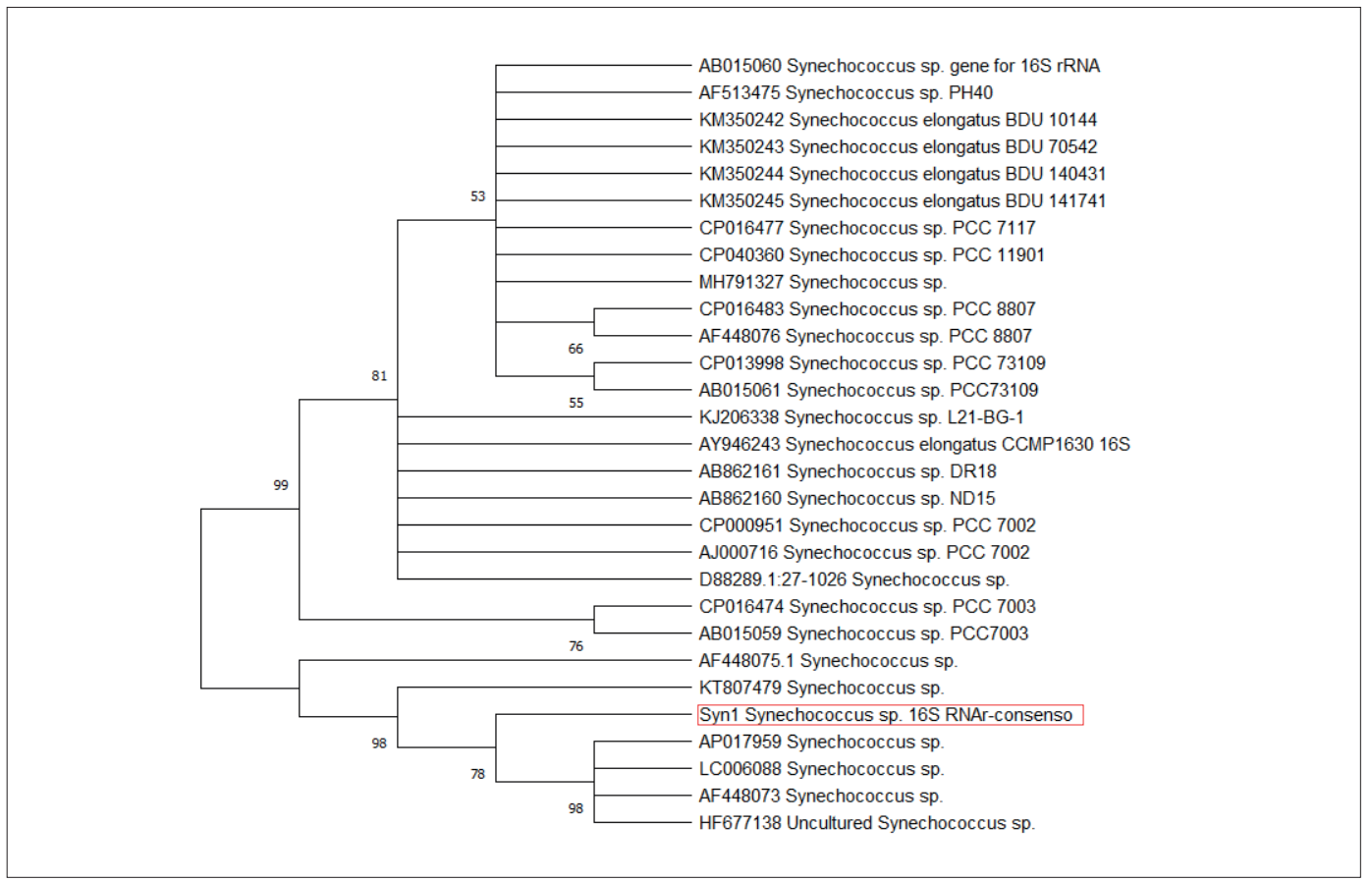

Figura 16. Dendrograma de agrupamiento para la muestra amplificada del gen $16 \mathrm{~S}$ RNAr. Método de agrupamiento por Máxima Verosimilitud (Maximum-likelihood), modelo de sustitución Jukes-Cantor (JC+ G) y aproximación de Bootstrapping de 1000 permutaciones. La cepa aislada en este estudio se representa como Syn1 Synechococcus sp. 16S RNAr-consenso. 


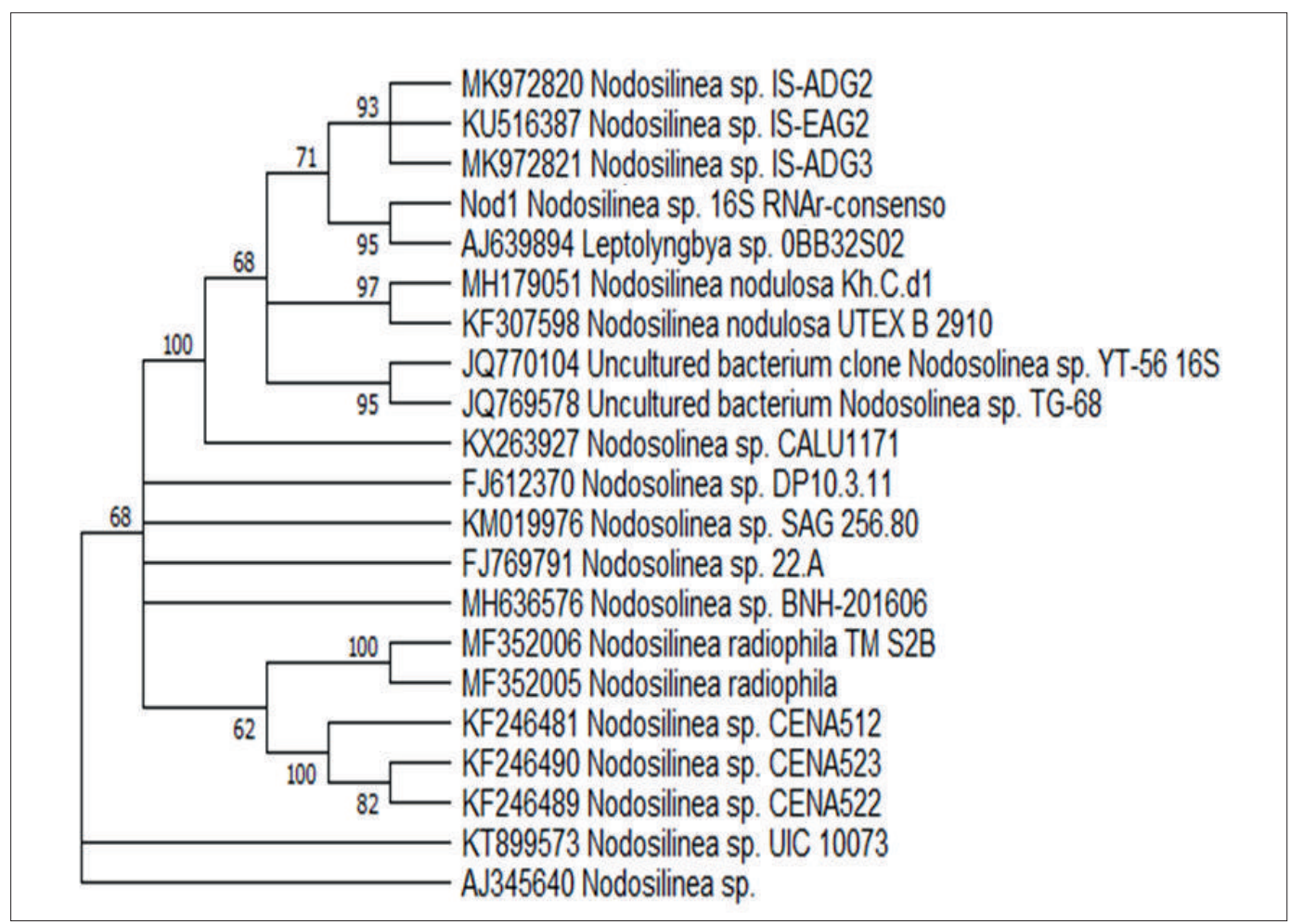

Figura 17. Dendrograma de agrupamiento para la muestra amplificada del gen $16 \mathrm{~S}$ RNAr. Método de agrupamiento por Máxima Verosimilitud (Maximum-likelihood), modelo de sustitución Kimura 2 - parámetros $(\mathrm{K} 2+\mathrm{G}+\mathrm{l})$ y aproximación de Bootstrapping de 1000 permutaciones. La cepa aislada en este estudio se representa como Nod1 Nodosilinea sp. 16S RNAr-consenso.

una identidad del 95\%. La estructura de los dominios conservados 16S RNAr proporciona confirmación adicional de la similitud filogenética entre todas las especies de Nodosilinea sp. presentada en este estudio y la del NCBI (Fig. 17). Por ello, es importante hacer énfasis en que el género Nodosilinea fue descrito hace menos de una década, muchas secuencias en bases de datos moleculares pertenecen al clado Nodosilinea, como se ilustra en el análisis filogenético. Es un género que alberga especies crípticas.

\section{Conclusiones}

Los resultados obtenidos del enfoque polifásico mediante caracteres fenotípicos y genotípicos, permitió la identificación taxonómica de tres cepas de microorganismos fitoplanctónicos aislados de piscinas de oxidación de la comuna de Engabao, en la provincia del Guayas, Ecuador, se desarrollaron en medios de cultivos óptimos: BG11 pH 7.8 y Zarrouk 9.9.

La extracción y purificación de ADNg con biomasa cultivada durante 7 días demostró que la cantidad y calidad del ADNg era óptima para la amplificación por PCR y secuenciación.

Mediante el uso de técnicas moleculares con los primers universales: ITS2, ITS y LSU, se identificó una cepa de microalga hasta nivel de especie: Chlorella sorokiniana, mientras que, empleando el primer $16 \mathrm{~S}$ RNAr se identificó a nivel de género dos cepas de cianobacterias: Synechococcus sp. y Nodosilinea sp.

Las secuencias consenso obtenidas de la amplificación demostraron que a pesar de no emplear cebadores específicos, el uso de varias regiones aplicadas a una misma especie, aumenta la confiablidad en la identificación taxonómica y filogenética.

\section{Recomendaciones}

- Seguir investigando las especies fitoplanctónicas que habitan en las piscinas de oxidación de la comuna Engabao y las aplicaciones biotecnológicas para contribuir con la economía de la comuna, cambiando la matriz productiva.

- Emplear enfoques polifásicos para determinar la identidad taxonómica de varias especies aisladas de aguas residuales.

- Uso de primers específicos para la amplificación de ADNg de cepas fitoplanctónicas.

- Aplicar varios primers para una misma especie como son ITS, 16S RNAr, 18S RNAr, SSU y 23S RNAr, con el fin de establecer relaciones taxonómicas 
y filogenéticas más confiables a nivel género y especie.

- Actualización de la base de datos de GenBank en relación a especies crípticas como es el caso de las cianobacterias.

\section{Referencias}

Allen, M. M. 1968. Simple conditions for growth of unicellular Blue-Green Algae on plates. Journal of Phycology, 4(1), 1-4. https://doi.org/10.1111/J.1529-8817.1968.TB04667.X

Amara, A. A., y Steinbüchel, A. 2013. New Medium for Pharmaceutical Grade Arthrospira. International Journal of Bacteriology, 2013, 1-9. https://doi. org/10.1155/2013/203432

Andersen, R. A. 2005. Algal Culturing Techniques (p. 578). Phycological Society of America.

Andrade, C., Vera, A., Cárdenas, C., y Morales, E. 2009. Biomass production of microalga Scenedesmus sp. with wastewater from fishery. Revista Técnica de La Facultad de Ingeniería Universidad del Zulia, 32(2), 126-134.

Arredondo, B., Voltolina, D., Zenteno, T., y Arce, M. 2007. Métodos y herramientas analiticas en la evaluación de la biomasa microalgal. Centro de Investigaciones Biológicas del Norte, S. C. http://dspace.cibnor.mx:8080/ handle/123456789/1403

Bain, B. J. 1998. Lymphomas and reactive lymphoid lesions in HIV infection. Haematology Blood Reviews, 12(2), 154-162.

Ballesteros, I., Terán, P., Guamán-Burneo, C., González, N., Cruz, A., y Castillejo, P. 2021. DNA barcoding approach to characterize microalgae isolated from freshwater systems in Ecuador. Biodiversidad Neotropical, 7(1), 170-183. https: / /doi.org/10.1080/23766808.2021.1920296

Barsanti, L., y Gualtieri, P. 2014. Algae: Anatomy, Biochemistry, and Biotechnology. CRC Press. https://doi. org/10.1201/B16544

Baurain, D., Renquin, L., Grubisic, S., Scheldeman, P., Belay, A., y Wilmotte, A. 2002. Remarkable Conservation of Internally Transcribed Spacer sequences of Arthrospira ("Spirulina") (Cyanophyceae, Cyanobacteria) strains from four continents and of recent and 30 year old dried samples from Africa. Journal of Phycology, 38(2), 384-393. https:// doi.org/10.1046/J.1529-8817.2002.01010.X

Begum, H., Yusoff, F. M. D., Banerjee, S., Khatoon, H., y Shariff, M. 2016. Availability and Utilization of Pigments from Microalgae. Critical Reviews in Food Science and Nutrition, 56(13), 2209-2222. https://doi.org/10.1080/10 408398.2013.764841

Berrendero, E., Perona, E., y Mateo, P. 2008. Genetic and morphological characterization of Rivularia and Calothrix (Nostocales, Cyanobacteria) from running water. International Journal of Systematic and Evolutionary Microbiology, 58(2), 447-460. https://doi.org/10.1099/ IJS.0.65273-0

Blaxter, M. L. 2004. The promise of a DNA taxonomy. Philosophical Transactions of the Royal Society of London. Series B: Biological Sciences, 359(1444), 669-679. https:// doi.org/10.1098/RSTB.2003.1447

Brennan, L., y Owende, P. 2010. Biofuels from microalgae-A review of technologies for production, processing, and extractions of biofuels and co-products. Renewable and Sustainable Energy Reviews, 14(2), 557-577. https://doi. org/10.1016/J.RSER.2009.10.009

Brodie, J., y Lewis, J. 2007. Unravelling the algae: the past, present, and future of algal systematics. CRC Press.

Carty, S., y Hall, J. D. 2002. Desmids and Dinoflagellates of Ecuador. Journal of Phycology, 38(1), 2-12. https://doi. org/10.1046/J.1529-8817.38.S1.54.X

Chaïb, S., Pistevos, J. C. A., Bertrand, C., y Bonnard, I.
2021. Allelopathy and allelochemicals from microalgae: An innovative source for bio-herbicidal compounds and biocontrol research. Algal Research, 54(2), 102-213. https: / /doi.org/10.1016/J.ALGAL.2021.102213

Chan, M. C., Ho, S. H., Lee, D. J., Chen, C. Y., Huang, C. C., y Chang, J. S. 2013. Characterization, extraction and purification of lutein produced by an indigenous microalga Scenedesmus obliquus CNW-N. Biochemical Engineering Journal, 78, 24-31. https://doi.org/10.1016/J. BEJ.2012.11.017

Chen, S., Yao, H., Han, J., Liu, C., Song, J., Shi, L., Zhu, Y., Ma, X., Gao, T., Pang, X., Luo, K., Li, Y., Li, X., Jia, X., Lin, Y., y Leon, C. 2010. Validation of the ITS2 Region as a Novel DNA Barcode for Identifying Medicinal Plant Species. PLOS ONE, 5(1), 86-13. https://doi.org/10.1371/JOURNAL. PONE.0008613

Cheng, X., Chen, X., Su, X., Zhao, H., Han, M., Bo, C., Xu, J., Bai, H., y Ning, K. 2014. DNA Extraction Protocol for Biological Ingredient Analysis of Liuwei Dihuang Wan. Genomics, Proteomics and Bioinformatics, 12(3), 137-143. https: //doi.org/10.1016/J.GPB.2014.03.002

Chun, J., Lee, J.-H., Jung, Y., Kim, M., Kim, S., Kim, B. K., y Lim, Y.-W. 2007. EzTaxon: a web-based tool for the identification of prokaryotes based on $16 \mathrm{~S}$ ribosomal RNA gene sequences. International Journal of Systematic and Evolutionary Microbiology, 57(10), 2259-2261. https:// doi.org/10.1099/IJS.0.64915-0

Colla, G., y Rouphael, Y. 2020. Microalgae: New Source of Plant Biostimulants. Agronomy 2020, 10(9), 1240. https:// doi.org/10.3390/AGRONOMY10091240

Conklin, K. Y., Stancheva, R., Otten, T. G., Fadness, R., Boyer, G. L., Read, B., Zhang, X., y Sheath, R. G. 2020. Molecular and morphological characterization of a novel dihydroanatoxin-a producing Microcoleus species (cyanobacteria) from the Russian River, California, USA. Harmful Algae, 93, 101767. https://doi.org/10.1016/J. HAL.2020.101767

Cornejo, A., Serrato, A., Rendón, B., y Rocha, M. 2015. Herramientas moleculares aplicadas en ecología: aspectos teóricos y prácticos. Herramientas Moleculares Aplicadas en Ecología, 13(3), 175-202.

Darienko, T., Gustavs, L., Eggert, A., Wolf, W., y Pröschold, T. 2015. Evaluating the species boundaries of green microalgae (Coccomyxa, Trebouxiophyceae, Chlorophyta) using integrative taxonomy and DNA Barcoding with further implications for the species identification in environmental samples. PLOS ONE, 10(6), 127-838. https://doi. org/10.1371/JOURNAL.PONE.0127838

Davydov, D., Shalygin, S., y Vilnet, A. 2020. New cyanobacterium Nodosilinea svalbardensis sp. nov. (Prochlorotrichaceae, Synechococcales) isolated from alluvium in Mimer river valley of the Svalbard archipelago. Phytotaxa, 442(2), 61-79.

de-Bashan, L. E., Trejo, A., Huss, V. A. R., Hernandez, J. P., y Bashan, Y. 2008. Chlorella sorokiniana UTEX 2805 a heat and intense, sunlight-tolerant microalga with potential for removing ammonium from wastewater. Bioresource Technology, 99(11), 4980-4989. https://doi. org/10.1016/J.BIORTECH.2007.09.065

Demay, J., Bernard, C., Reinhardt, A., y Marie, B. 2019. Natural Products from Cyanobacteria: Focus on beneficial activities. Marine Drugs, 17(6), 320. https://doi. org/10.3390/MD17060320

Doyle, J. J., y Doyle. 1897. A rapid DNA isolation procedure for small quantities of fresh leaf tissue. Phytochemical Bulletin, 19, 11-15. https://www.scirp.org/reference/ ReferencesPapers.aspx?ReferencelD=695827

Dufossé, L., Galaup, P., Yaron, A., Arad, S. M., Blanc, P., Murthy, K. N. C., y Ravishankar, G. A. 2005. Microorganisms and microalgae as sources of pigments for food use: a scientific oddity or an industrial reality? Trends in Food Science \& Technology, 16(9), 389-406. https://doi. 
org/10.1016/J.TIFS.2005.02.006

Ende, S. S. W., y Noke, A. 2019. Heterotrophic microalgae production on food waste and by-products. Journal of Applied Phycology 2018 31:3, 31(3), 1565-1571. https:// doi.org/10.1007/S10811-018-1697-6

Falciatore, A., Jaubert, M., Bouly, J.-P., Bailleul, B., y Mock, T. 2020. Diatom Molecular Research Comes of Age: Model Species for Studying Phytoplankton Biology and Diversity. The Plant Cell, 32(3), 547-572. https://doi.org/10.1105/ TPC.19.00158

Fawley, M. W. y Fawley, K. P. 2020. Identification of eukaryotic microalgal strains. Journal of Applied Phycology 2020 32:5, 32(5), 2699-2709. https://doi.org/10.1007/S10811-02002190-5

Fernández-Aláez, C., Fernández-Aláez, M., Santiago, N. F., y Aboal, M. 2012. ID-tax. Catálogo y claves de identificación de organismos del grupo macrófitos utilizados como elementos de calidad en las redes de control de estado ecológico. Ministerio de Agricultura, Alimentación y Medio Ambiente: Madrid, Spain.

Fernández, E., Schnell, R., Ranum, L. P., Hussey, S. C., Silflow, C. D., y Lefebvre, P. A. 1989. Isolation and characterization of the nitrate reductase structural gene of Chlamydomonas reinhardtii. Proceedings of the National Academy of Sciences, 86(17), 6449-6453.

Ferrao-Filho, A., y Moscatelli, M. 2020. Recreational risk associated with the presence of Cyanobacteria in the Baixada de Jacarepaguá Lagoon Complex estuary, Rio de Janeiro, RJ, Brazil. SciELO, 2, 1-10. https://doi.org/doi. org/10.1590/SciELOPreprints. 1395

Fiore, M. F., Moon, D. H., Tsai, S. M., Lee, H., y Trevors, J. T. 2000. Miniprep DNA isolation from unicellular and filamentous Cyanobacteria. Journal of Microbiological Methods, 39(2), 159-169. https://doi.org/10.1016/S01677012(99)00110-4

Flores, F., Maldonado, S., y Ortiz, J. 2016. Identificación molecular de microalgas clorófitas del Ecuador. Departamento de Ciencias de La Vida y La Agricultura, 1-2.

Furtado, A. 2007. Isolamento, morfologia, análises moleculares e testes toxicológicos de cianobactérias em lagoa facultativa de sistema de estabilização (Cajati-SP) [Tese de Doutorado, Universidade de São Paulo]. https:// doi.org/10.11606/T.18.2007.TDE-29052008-220602

Gantar, M., y Svirčev, Z. 2008. Microalgae and Cianobacteria: Food for thought. Journal of Phycology, 44(2), 260-268. https://doi.org/10.1111/J.1529-8817.2008.00469.X

García, J., Pavía, M., García, T., Chirivella, J., y Serrano, A. 2017. Principios de Biotecnología y Bioingeniería en el cultivo de microalgas: importancia, problemas tecnológicos, tipos y sistemas de cultivos, crecimiento, factores limitantes, selección, aislamiento, escalado y caracterización bioquímica. Nereis, 9, 115-129. https:// doi.org/108.128.142.30

Gómez, O., Guerrero, M., Meneses, K., y Núñez, K. 2018. Identtificación de una coleeción de microalgas aisladas de Costa Rica mediante secuenciación de ADNr $18 \mathrm{~S}$. Acta Biológica Colombiana, 23(2), 199-204. https://doi. org/10.15446/ABC.V23N2.68088

Gouveia, L., Marques, A. E., Sousa, J. M., Moura, P., y Bandarra, N. M. 2010. Microalgae-source of natural bioactive molecules as functional ingredients. Food Science and Technology, Bull. Funct. Foods, 7(2), 21-37. https://doi.org/10.1616/1476-2137.15884

Greco, M., Sáez, C. A., Brown, M. T., y Bitonti, M. B. 2014. A Simple and Effective Method for High Quality Co-Extraction of Genomic DNA and Total RNA from Low Biomass Ectocarpus siliculosus, the model brown algae. PLOS ONE, 9(5), 96120. https://doi.org/10.1371/JOURNAL.PONE.0096470

Guamán, M., y González, N. 2016. Catálogo de microalgas y cianobacterias de agua dulce del Ecuador. Corporación Para La Investigación Energética, 143.

Guillard, R. R. L. 1973. Division rates. Handbook of
Phycological Methods: Culture Methods and Growth Measurements.

Haneda, R. N., Vieira, B. H., Fontes, S. R., Ombardi, G., Casali, C. A., \& Lombardi, A. T. 2015. Biochemical composition of Chlorella sorokiniana grown in a novel design of hybrid photobioreactor. J. Microb. Biochem. Technol., 7(2), 76082. https: //doi.org/10.4172/1948-5948.1000185

Hollingsworth, P. M., Forrest, L. L., Spouge, J. L., Hajibabaei, M., Ratnasingham, S., Bank, M. van der, Chase, M. W., Cowan, R. S., Erickson, D. L., Fazekas, A. J., Graham, S. W., James, K. E., Kim, K.-J., Kress, W. J., Schneider, H., AlphenStahl, J. van, Barrett, S. C. H., Berg, C. van den, Bogarin, D., ... y Little, D. P. 2009. A DNA barcode for land plants. Proceedings of the National Academy of Sciences, 106(31), 12794-12797. https://doi.org/10.1073/ PNAS.0905845106

Janssen, P. J., Morin, N., Mergeay, M., Leroy, B., Wattiez, R., Vallaeys, T., Waleron, K., Waleron, M., Wilmotte, A., Quillardet, P., Tandeau De Marsac, N., Talla, E., Zhang, C. C., y Leys, N. 2010. Genome sequence of the edible cyanobacterium Arthrospira sp. PCC 8005. Journal of Bacteriology, 192(9), 2465-2466. https://doi.org/10.1128/ JB.00116-10

Jeffrey, S. W., Wright, S. W., y Zapata, M. 2011. Microalgal classes and their signature pigments. Phytoplankton Pigments, 3-77. https://doi.org/10.1017/ CBO9780511732263.004

Johansen, J. R., Kovacik, L., Kaštovský, J., y Casamatta, D. A. 2011. A unique Pseudanabaenalean (Cyanobacteria) genus Nodosilinea gen. nov. based on morphological and molecular data. Journal of Phycology, 47, 1397-1412. https://doi.org/10.1111/j.1529-8817.2011.01077.x

Jung, P., Schermer, M., Briegel-Williams, L., Baumann, K., Leinweber, P., Karsten, U., Lehnert, L., Achilles, S., Bendix, J., y Büdel, B. 2019. Water availability shapes edaphic and lithic cyanobacterial communities in the Atacama desert. Journal of Phycology, 55(6), 1306-1318. https: // doi.org/10.1111/JPY.12908

Kalendar, R., Muterko, A., Shamekova, M., y Zhambakin, K. 2017. In silico PCR tools for a fast primer, probe, and advanced searching. Methods in Molecular Biology, 1620, 1-31. https://doi.org/10.1007/978-1-4939-7060-5_1

Kazi, M. A., Reddy, C. R. K., y Jha, B. 2013. Molecular Phylogeny and Barcoding of Caulerpa (Bryopsidales) Based on the tufA, rbcL, $18 \mathrm{~S}$ rDNA and ITS rDNA Genes. PLOS ONE, 8(12), 24-38. https://doi.org/10.1371/JOURNAL. PONE.0082438

Koksharova, O. A., Kravzova, T. R., Lazebnaya, I. V., Gorelova, O. A., Baulina, O. I., Lazebny, O. E., Fedorenko, T. A., y Lobakova, E. S. 2013. Molecular identification and ultrastructural and phylogenetic studies of cyanobacteria from association with the white sea hydroid Dynamena pumila (L., 1758). BioMed Research International, 2(3), 1-23. https: //doi.org/10.1155/2013/760681

Komárek, J., Kaštovský, J., Mareš, J., y Johansen, J. R. 2014. Taxonomic classification of cyanoprokaryotes (cyanobacterial genera) 2014, using a polyphasic approach. Preslia, 86(4), 295-335.

Krienitz, L., Wolf, M., Hegewald, E., y Hepperle, D. 2002. Systematics of Coccoid Green Algae: Morphology vs. $18 \mathrm{~S}$ rRNA Gene Phylogeny. Journal of Phycology, 38(s1), 19-20. https://doi.org/10.1046/J.1529-8817.38.S1.57.X

Kumar, S., Stecher, G., Li, M., Knyaz, C., y Tamura, K. 2018. MEGA X: Molecular Evolutionary Genetics Analysis across Computing Platforms. Molecular Biology and Evolution, 35(6), 1547. https://doi.org/10.1093/MOLBEV/MSY096

Lebonah, D. E., Dileep, A., Chandrasekhar, K., Sreevani, S., Sreedevi, B., y Pramoda Kumari, J. 2014. DNA Barcoding on Bacteria: A Review. Advances in Biology, 2014, 1-9. https://doi.org/10.1155/2014/541787

Lee, R. E. 2008. Microalgae. En Phycology, Fourth edition (p. 547). Cambridge University Press. https://doi.org/978-0- 
521-86408-4

Lloyd, C., Tan, K. H., Lim, K. L., Valu, V. G., Fun, S. M. Y., Chye, T. R., Mak, H. M., Sim, W. X., Musa, S. L., Ng, J. J. Q., Bte Nordin, N. S., Bte Md Aidzil, N., Eng, Z. Y. W., Manickavasagam, P., y New, J. Y. 2021. Identification of microalgae cultured in Bold's Basal medium from freshwater samples, from a high-rise city. Scientific Reports 2021 11:1, 11(1), 1-6. https://doi.org/10.1038/ s41598-021-84112-0

López-Osorio, R., Cañón-Páez, M. L., y Gracia-Escobar, M. F. 2011. Catálogo de Fitoplancton de la Bahía de Cartagena, Bahía Portete y Agua de Lastre. In Dirección General Marítima- Centro de Investigaciones Oceanográficas e Hidrográficas del Caribe. Ed. Dimar, Serie de Publicaciones Especiales $\mathrm{CIOH}$ (p. 135). https://doi. org/10.26640/52.2011

Luo, W., Pröschold, T., Bock, C., y Krienitz, L. 2010. Generic concept in Chlorella-related coccoid green algae (Chlorophyta, Trebouxiophyceae). Plant Biology (Stuttgart, Germany), 12(3), 545-553. https://doi.org/10.1111/ J.1438-8677.2009.00221.X

Madden, T. (2012). The BLAST Sequence Analysis Tool. In The NCBI handbook (2nd ed., p. 15).

McCourt, R. M., Park, J., Hewitt, D. A., y Karol, K. G. 2002. Phylogeny of the Conjugating Green Algae (Zygnematales and Desmidiales) Based on Plastid and Mitochondrial Gene Sequences. Journal of Phycology, 38, 26-26. https://doi. org/10.1046/J.1529-8817.38.S1.75.X

Molins, A., Moya, P., García-Breijo, F. J., Reig-Armiñana, J., y Barreno, E. 2018. Molecular and morphological diversity of Trebouxia microalgae in sphaerothallioid Circinaria spp. lichens. Journal of Phycology, 54(4), 494-504. https://doi. org/10.1111/JPY. 12751

Morales, E., Luna, V., Navarro, L., Santana, V., Gordillo, A., y Arévalo, A. 2013. Diversidad de microalgas y cianobacterias en muestras provenientes de diferentes provincias del Ecuador, destinadas a una colección de cultivos. Revista Ecuatoriana de Medicina y Ciencias Biológicas, 34(1-2), 129-149. https://doi.org/10.26807/REMCB.V34I1-2.240

Morales, F. 2015. Associação da ocorrência de cianobactérias às variações de qualidade do efluente na lagoa de estabilização de Santa Eudóxia - São Carlos, SP e suas interferências no corpo receptor. Centro de Ciencias Exactas y Tecnología, 45-67.

Moreno, M., Ortiz, C., Sánchez, J., Padilla, J., y Otero, A. 2012. Evaluación del crecimiento de la microalga Chlorella sorokiniana en diferentes medios de cultivo en condiciones autotróficas y mixotróficas. Orinoquia, 16(1), 11-20. https: / / www.redalyc.org/articulo.oa?id $=89625076002$

Morin, N., Vallaeys, T., Hendrickx, L., Natalie, L., y Wilmotte, A. 2010. An efficient DNA isolation protocol for filamentous cyanobacteria of the genus Arthrospira. Journal of Microbiological Methods, 80(2), 148-154. https://doi. org/10.1016/j.mimet.2009.11.012

Moronta, R., Mora, R., y Morales, E. 2006. Respuesta de la microalga Chlorella sorokiniana al $\mathrm{pH}$, salinidad y temperatura en condiciones axénicas y no axénicas. Revista de La Facultad de Agronomía, 23(1), 28-43.

Nägeli, C. 1849. Gattungen einzelliger Algen physiologisch und systematisch bearheitet . Friedrich Schulthess.

Neofotis, P., Huang, A., Sury, K., Chang, W., Joseph, F., Gabr, A., Twary, S., Qiu, W., Holguin, O., y Polle, J. E. W. 2016. Characterization and classification of highly productive microalgae strains discovered for biofuel and bioproduct generation. Algal Research, 15, 164-178. https://doi. org/10.1016/J.ALGAL.2016.01.007

Nicoletti, M. 2016. Microalgae Nutraceuticals. Foods, 5(3), 54. https://doi.org/10.3390/FOODS5030054

Niiyama, Y. 2012. New classification system for Oscillatoriales, Cyanophyceae. Japanese Journal of Limnology (Rikusuigaku Zasshi), 73(3), 187-196. https:// doi.org/10.3739/RIKUSUI.73.187
Oliveira, E. D. C., Castelo-Branco, R., Silva, L., Silva, N. Azevedo, J., Vasconcelos, V., Faustino, S., y Cunha, A. 2019. First detection of microcystin-Ir in the amazon river at the drinking water treatment plant of the municipality of Macapá, Brazil. Toxins, 11(11). https://doi.org/10.3390/ TOXINS11110669

Osorio, K., Pietrasiak, N., Bohunická, M., Miscoe, L. H., Kováčik, L., Martin, M. P., y Johansen, J. R. 2014. Seven new species of Oculatella (Pseudanabaenales, Cyanobacteria): taxonomically recognizing cryptic diversification. European Journal of Phycology, 49(4), 450-470. https://doi.org/10.1 080/09670262.2014.976843

Padisák, J., Vasas, G., y Borics, G. 2015. Phycogeography of freshwater phytoplankton: traditional knowledge and new molecular tools. Hydrobiologia 2015 764:1, 764(1), 3-27. https://doi.org/10.1007/S10750-015-2259-4

Pancha, I., Chokshi, K., George, B., Ghosh, T., Paliwal, C., Maurya, R., y Mishra, S. 2014. Nitrogen stress triggered biochemical and morphological changes in the microalgae Scenedesmus sp. CCNM 1077. Bioresource Technology, 156, 146-154. https://doi.org/10.1016/J. BIORTECH.2014.01.025

Pangestuti, R., Suryaningtyas, I. T., Siahaan, E. A., y Kim, S.-K. 2020. Cosmetics and Cosmeceutical Applications of Microalgae Pigments. Pigments from Microalgae Handbook, 1(1), 611-633. https://doi.org/10.1007/978-3-030-50971. 2_25

Pineda, R., Martínez, F., Garduño, G., y Olvera, R. 2011. Caracterización morfológica y molecular de cianobacterias filamentosas aisladas de florecimientos de tres lagos urbanos eutróficos de la ciudad de México. POLIBOTANICA, $31,31-50$

Radha, S., Fathima, A. A., Iyappan, S., y Ramya, M. 2012 Direct colony PCR for rapid identification of varied microalgae from freshwater environment. Journal of Applied Phycology 2012 25:2, 25(2), 609-613. https://doi. org/10.1007/S10811-012-9895-0

Radzi, R., Muangmai, N., Broady, P., Omar, W. M. W., Lavoue, S., Convey, P., y Merican, F. 2019. Nodosilinea signiensis sp. nov. (Leptolyngbyaceae, Synechococcales), a new terrestrial cyanobacterium isolated from mats collected on Signy Island, South Orkney Islands, Antarctica. PLOS ONE, 14(11), e0224395. https://doi.org/10.1371/JOURNAL. PONE.0224395

Rippka, R. 1988. Recognition and Identification of Cyanobacteria. Methods in Enzymology, 167, 28-67. https: / /doi.org/10.1016/0076-6879(88)67005-4

Romero, J. 2019. Caracterización de compuestos antioxidantes carotenoides y polifenoles presentes en las microalgas Chlorella sp. y Nannochloropsis oculata cultivadas in vitro con potencial nutricional [Tesis Magister, Universidad de Cuenca]. https://fiqa.epn.edu.ec/index.php/nmaestrias/ biociencias-aplicadas-mbd

Rosales, N., Ortega, J., Mora, R., y Morales, E. 2005. Influencia de la salinidad sobre crecimiento y composición bioquímica de la cianobacteria Synechococcus sp. Ciencias Marinas, 31(2), 349-355. http://www.scielo.org.mx/ scielo. php?pid=S0185-38802005000300003\&script $=$ sci_ arttext

Ruocco, N., Mutalipassi, M., Pollio, A., Costantini, S., Costantini, M., y Zupo, V. 2018. First evidence of Halomicronema metazoicum (Cyanobacteria) free-living on Posidonia oceanica leaves. PLOS ONE, 13(10), 49-54. https://doi.org/10.1371/JOURNAL.PONE.0204954

Saiki, R., Gelfand, D., Stoffel, S., Scharf, S., Higuchi, R., Horn, G., Mullis, K., y Erlich, H. 1988. Primer-directed enzymatic amplification of DNA with a thermostable DNA polymerase. Science, 239(4839), 487-491. https://doi. org/10.1126/SCIENCE.239.4839.487

Sambrook, J., y Russell, D. W. 2001. Molecular CloningSambrook \& Russel-Vol. 1, 2, 3. Cold Springs Harbour Laboratory Press. 
Samylina, O. S., Sapozhnikov, F. V., Gainanova, O. Y., Ryabova, A. V., Nikitin, M. A., y Sorokin, D. Y. 2014. Algo-bacterial communities of the Kulunda steppe (Altai Region, Russia) Soda Lakes. Microbiology 2014 83:6, 83(6), 849-860. https://doi.org/10.1134/S0026261714060162

Schuelter, A. R., Kroumov, A. D., Hinterholz, C. L., Fiorini, A., Trigueros, D. E. G., Vendruscolo, E. G., Zaharieva, M. M., y Módenes, A. N. 2019. Isolation and identification of new microalgae strains with antibacterial activity on food-borne pathogens. Engineering approach to optimize synthesis of desired metabolites. Biochemical Engineering Journal, 144, 28-39. https://doi.org/10.1016/J.BEJ.2019.01.007

Shihira, I., y Krauss, R. W. 1965. Chlorella Physiology and Taxonomy of Forty-one Isolates. Maryland: Universidad de Maryland, College Park, 1-97.

Silva, C. S. P., Genuário, D. B., Vaz, M. G. M. V., y Fiore, M. F. 2014. Phylogeny of culturable cyanobacteria from Brazilian mangroves. Systematic and Applied Microbiology, 37(2), 100-112. https://doi.org/10.1016/J.SYAPM.2013.12.003

Skulberg, O. M. 2000. Microalgae as a source of bioactive molecules - experience from cyanophyte research. Applied Phycology, 12(3), 341-348. https://doi. org/10.1023/A:1008140403621

Smetana, S., Sandmann, M., Rohn, S., Pleissner, D., y Heinz, V. 2017. Autotrophic and heterotrophic microalgae and cyanobacteria cultivation for food and feed: life cycle assessment. Bioresource Technology, 245, 162-170. https://doi.org/10.1016/J.BIORTECH.2017.08.113

Solovchenko, A. E., Gorelova, O. A., Baulina, O. I., Selyakh, I. O., Semenova, L. R., Chivkunova, O. B., Scherbakov, P. N., y Lobakova, E. S. 2015. Physiological plasticity of symbiotic Desmodesmus (Chlorophyceae) isolated from taxonomically distant white sea invertebrates. Russian Journal of Plant Physiology, 62(5), 653-663. https://doi. org/10.1134/S1021443715050167

Strickland, J., y Parsons, T. 1972. A practical handbook of seawater analysis (167th ed.). Fisheries Research Board of Canada.

Talling, J. F., y Driver, D. 1961. Some problems in the estimation of chlorophyll $a$ En Phytoplankton: proceedings, Conference of Primary Productivity Measurement, Marine and Freshwater. En M. S Doty (pp. 142-146).

Tello, A., y Guerrero, M. 2016. Purificación de ADN genómico y ARN total de tres especies de microalgas oleaginosas Ankistrodesmus sp. Chlorella sp. y Scenedesmus sp. [Tesis de grado, Universidad Científica del Perú]. http:// repositorio.ucp.edu.pe/handle/UCP/900

Tenorio, L., HernándeZ, H., y Aguirre, M. 2018. Manual para obtención de cepas de microalgas. Instituto del Mar del Perú, 45(2), 277-291. https://repositorio.imarpe.gob.pe/ handle/20.500.12958/3285

Tomitani, A., Knoll, A. H., Cavanaugh, C. M., y Ohno, T. 2006. The evolutionary diversification of cyanobacteria: Molecular-phylogenetic and paleontological perspectives. Proceedings of the National Academy of Sciences, 103(14), 5442-5447. https://doi.org/10.1073/PNAS.0600999103

Turner, S., Pryer, K. M., Miao, V. P. W., y Palmer, J. D. 1999. Investigating deep phylogenetic relationships among cyanobacteria and plastids by small subunit rRNA sequence analysis. Journal of Eukaryotic Microbiology, 46, 327-338.

Üveges, V., Tapolczai, K., Krienitz, L., y Padisák, J. 2012. Photosynthetic characteristics and physiological plasticity of an Aphanizomenon flos-aquae (Cyanobacteria, Nostocaceae) winter bloom in a deep oligo-mesotrophic lake (Lake Stechlin, Germany). Phytoplankton Responses to Human Impacts at Different Scales, 263-272. https:// doi.org/10.1007/978-94-007-5790-5_20

Valenzuela-González, F., Casillas-Hernández, R., Villalpando, E., y Vargas-Albores, F. 2015. El gen ARNr 16S en el estudio de comunidades microbianas marinas. Ciencias Marinas, 41(4), 297-313.

Valério, E., Chambel, L., Paulino, S., Faria, N., Pereira, P., y Tenreiro, R. 2009. Molecular identification, typing and traceability of Cyanobacteria from freshwater reservoirs. Microbiology, 155(2), 642-656. https://doi.org/10.1099/ MIC.0.022848-0

Vásquez, J., Gutiérrez, J., Ramírez, E., Mondragón, M., Partida, L., Johansen, J., y Molina, J. 2018. Nodosilinea chupicuarensis sp. nov. (Leptolyngbyaceae, Synechococcales) una Cianobacteria subaerial aislada de un monumento de piedra en el centro de México. Phytotaxa, 334(2), 167-182. https://doi.org/10.11646/ PHYTOTAXA.334.2.6

Vieira, M. V., Pastrana, L. M., y Fuciños, P. 2020. Microalgae encapsulation systems for food, Pharmaceutical and Cosmetics Applications. Marine Drugs, 18(12), 644. https://doi.org/10.3390/MD18120644

Vijayakumar, S., y Menakha, M. 2015. Pharmaceutical applications of cyanobacteria-A review. Journal of Acute Medicine, 5(1), 15-23. https://doi.org/10.1016/J. JACME.2015.02.004

Vilgalys, R., y Hester, M. 1990. Rapid genetic identification and mapping of enzymatically amplified ribosomal DNA from several Cryptococcus species. Journal of Bacteriology, 172(8), 4238-4246. https://doi.org/10.1128/ JB.172.8.4238-4246.1990

Wan, M.-X., Wang, R.-M., Xia, J.-L., Rosenberg, J. N., Nie, Z.Y., Kobayashi, N., Oyler, G. A., y Betenbaugh, M. J. 2012. Physiological evaluation of a new Chlorella sorokiniana isolate for its biomass production and lipid accumulation in photoautotrophic and heterotrophic cultures. Biotechnology and Bioengineering, 109(8), 1958-1964. https://doi.org/10.1002/BIT.24477

Waterbury, J. 2006. The cyanobacteria: isolation purification and identification. En The Prokaryotes (Vol. 4, pp. 10531073). https://doi.org/10.1007/0-387-30744-3_38

Wehr, J. D., y Sheath, R. G. 2003. Freshwater Algae of North America. En Ecology and Classification.

Wehr, J. D., Sheath, R. G., y Kociolek, J. P. 2015. Introduction to the Freshwater Algae. En Freshwater Algae of North America: Ecology and Classification (pp. 1-11). Academic Press. https://doi.org/10.1016/B978-0-12-3858764.00001-3

White, T. J., Bruns, T., Lee, S., y Taylor, J. 1990. Amplification and direct sequencing of fungal ribosomal RNA genes for phylogenetics. PCR Protocols: A Guide to Methods and Applications, 18(1), 315-322.

Wu, X., Zarka, A., y Boussiba, S. 2000. A Simplified Protocol for Preparing DNA from Filamentous Cyanobacteria. Plant Molecular Biology Reporter, 18(4), 385-392. https://doi. org/10.1007/BF02825067

Yábar, C. 2003. Manual de procedimientos de electroforesis para proteínas y ADN. Serie de Normas Técnicas, 38, 1.

Yarza, P., Yilmaz, P., Pruesse, E., Glöckner, F. O., Ludwig, W., Schleifer, K.-H., Whitman, W. B., Euzéby, J., Amann, R., y Rosselló-Móra, R. 2014. Uniting the classification of cultured and uncultured bacteria and archaea using $16 \mathrm{~S}$ rRNA gene sequences. Nature Reviews Microbiology 2014 12:9, 12(9), 635-645. https://doi.org/10.1038/ nrmicro3330

Yun, H. S., Kim, Y. S., y Yoon, H. S. 2020. Characterization of Chlorella sorokiniana and Chlorella vulgaris fatty acid components under a wide range of light intensity and growth temperature for their use as biological resources. Heliyon, 6(7), 44-47. https://doi.org/10.1016/J. HELIYON.2020.E04447

Zarrouk, C. 1966. Contribution to the study of a Cyanophyceae influence of various physical and chemical factors on growth and phototsynthesis Spirulina maxima. University of Paris, 74. https://ci.nii.ac.jp/naid/10003539662

Zhou, W., Ding, D., Yang, Q., Ahmad, M., Zhang, Y., Lin, X., Zhang, Y., Ling, J., y Dong, J. 2018. Marileptolyngbya sina gen. nov., sp. nov. and Salileptolyngbya diazotrophicum gen. nov., sp. nov. (Synechococcales, Cyanobacteria), 
species of cyanobacteria isolated from a marine ecosystem. Phytotaxa, 383(1), 75-92. https://doi.org/10.11646/ phytotaxa.383.1.4

Zupo, V., Mutalipassi, M., Ruocco, N., Glaviano, F., Pollio, A., Langellotti, A. L., Romano, G., y Costantini, M. 2019. Distribution of toxigenic Halomicronema spp. in adjacent environments on the Island of Ischia: Comparison of strains from thermal waters and free living in Posidonia Oceanica meadows. Toxins 2019, 11(2): 99. https://doi. org/10.3390/TOXINS11020099 